\title{
HEPA Filter Jointer
}

\author{
RECEIVED \\ APR 081998 \\ OSTI
}

19980427055

\section{DIIC QUALTTY MUEPEUTED 3}

\section{Los Alamos \\ NATIONAL LABORATORY}

Los Alamos National Laboratory is operated by the University of California for the United States Department of Energy under contract W-7405-ENG-36. 
Edited by Lynne Atencio, Group CIC-1

An Affirmative Action/Equal Opportunity Employer

This report was prepared as an account of work sponsored by an agency of the United States Government. Neither The Regents of the University of California, the United States Government nor any agency thereof, nor any of their employees, makes any warranty, express or implied, or assumes any legal liability or responsibility for the accuracy, completeness, or usefulness of any information, apparatus, product, or process disclosed, or represents that its use would not infringe privately owned rights. Reference herein to any specific commercial product, process, or service by trade name, trademark, manufacturer, or otherwise, does not necessarily constitute or imply its endorsement, recommendation, or favoring by The Regents of the University of California, the United States Government, or any agency thereof. The views and opinions of authors expressed herein do not necessarily state or reflect those of The Regents of the University of California, the United States Government, or any agency thereof. Los Alamos National Laboratory strongly supports academic freedom and a researcher's right to publish; as an institution, howeoer, the Laboratory does not endorse the viewpoint of a publication or guarantee its technical correctness. 


\section{HEPA Filter Jointer}

Dallas Hill

H. E. Martinez

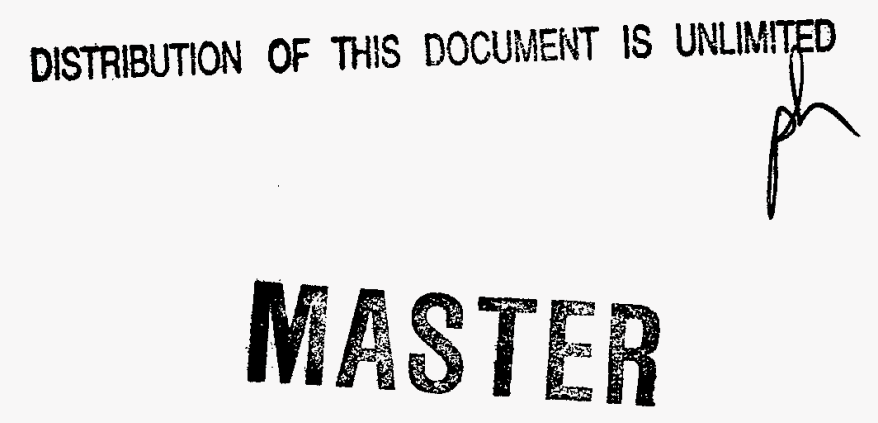

DTIC QUALITY INSPEEUTED a

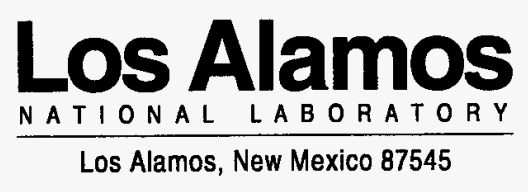




\title{
HEPA FILTER JOINTER
}

\section{by}

Dallas Hill and H. E. Martinez

\begin{abstract}
A HEPA filter jointer system was created to remove nitrate contaminated wood from the wooden frames of HEPA filters that are stored at the Rocky Flats Plant. A commercial jointer was chosen to remove the nitrated wood. The chips from the wood removal process are in the right form for caustic washing. The jointer was automated for safety and ease of operation. The HEPA filters are prepared for jointing by countersinking the nails with a modified air hammer. The equipment, computer program, and tests are described in this report.
\end{abstract}

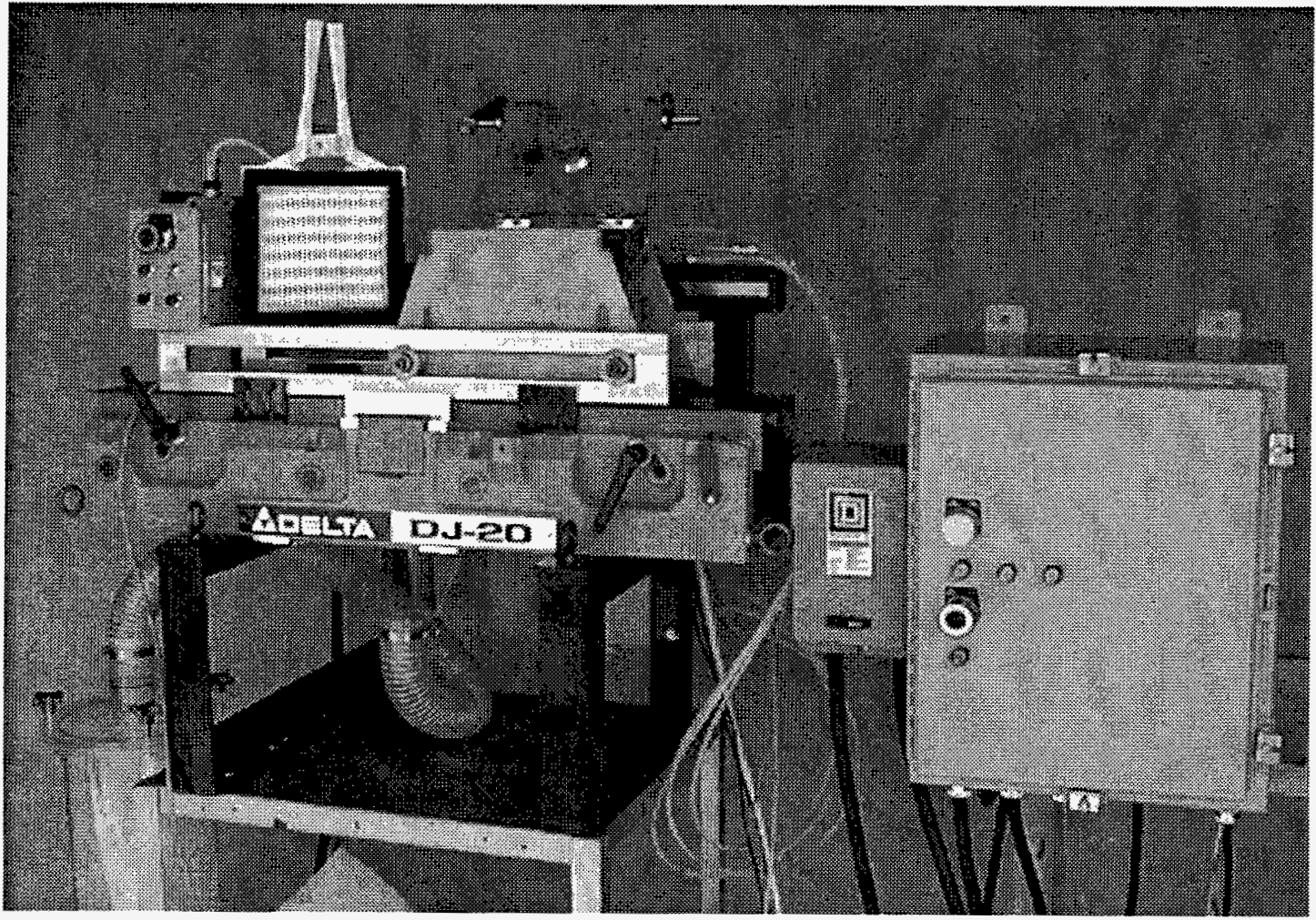

Hepa Filter Jointer 


\section{Introduction}

The HEPA (high-efficiency particulate air) filter jointer was created to remove nitrate contaminated wood from the frames of HEPA filters that are stored at Rocky Flats. The depth of nitrate contamination is less than 3 millimeters deep. A commercial jointer was chosen to remove the nitrated wood since the chips from the wood removal process are in the right form for a caustic wash. The jointer was automated for safety and ease of operation. To prepare the HEPA filters for jointing, an air hammer was modified to countersink nails below the material removal depth. The equipment, computer program, and tests are described in this report.

\section{HEPA Filter Jointer System}

The jointer system shown in Figure 1 was developed with off-the-shelf products as much as possible. The system was designed around a Delta DJ-20 8-inch-wide jointer. The jointer was modified by shortening the tables and removing the fence, base, and motor. Angle iron frames were made to attach the jointer base to the Franklin Miller shredder. A 480 VAC (voltage alternating current) three-phase motor attaches to the angle iron frames. A carriage with wheels, air cylinders, inert gas purge, and interlock switch was built to hold the HEPA filters. Rails to guide the wheels were attached to the jointer base. The carriage is moved across the jointer blades by a linear actuator. The linear actuator is attached to the jointer base by supports. The material collection system vacuums the wood chips into special sacks for washing. A clear housing, for visual inspection, holds the sack to collect the larger particles. The vacuum blower sucks the material from the jointer to the sack and then blows the fines into a micron filter bag enclosed in another clear housing. The system is automated by five relays using LabView to control the process. Two relays control the movement of the carriage, and three relays control the air solenoids, vacuum blower, and jointer motor. The electronics are mounted in NEMA (National Electrical Manufacturers Association) enclosures.

\section{HEPA Filter Operational Procedure}

\section{Prepare system for operation}

1. Observe that the equipment is in a ready state for operation and is clear for startup.

a. Check to see if the filter bags are full.

If the filter bag is full, follow the bag change-out instructions from procedure III.

b. Check for loose bolts.

c. Inspect the blades for nicks.

If nicked, follow the blade change-out instructions from procedure IV.

2. Energize the power sources.

a. $115 \mathrm{VAC} 30 \mathrm{~A}$.

b. 480 VAC 20 A or less. 


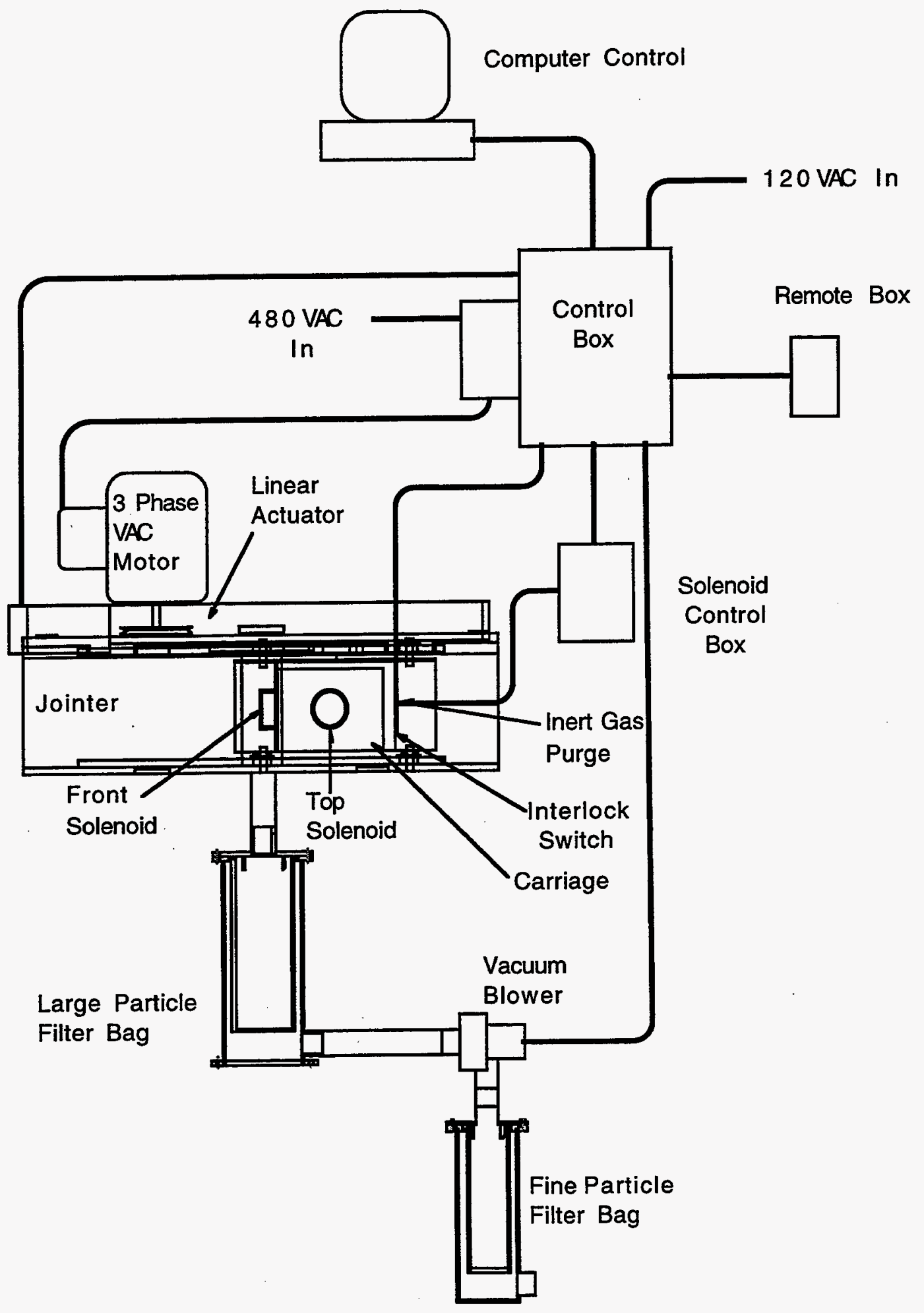

Figure 1. System schematic. 
3. Connect the air lines to the $60 \mathrm{psi}$ inert gas supply.

4. Start the computer and launch the LabView program.

5. Load the carriage with a filter that has the nails/screws countersunk.

6. Close the lid and lock it.

\section{Operation}

1. Start the LabView control program (click on the start button).

a. The program will pass one side of the filter over the jointer four times and then pause, waiting for the operator to turn the filter over to a new side.

b. If there are any operational problems

- push the emergency stop button on the remote control or the electrical enclosure, and

- stop the LabView program before the emergency button is reset.

c. If the carriage does not move, check that the emergency stop buttons on the remote control and electronics enclosure are pulled out (reset) and that the lid on the carriage is properly closed.

2. After the fourth pass on the first side of the filter, the program will shut down the jointer/vacuum system and ask the operator to rotate the filter.

a. Open the carriage lid.

b. Lift the HEPA filter out of the carriage with the special tongs.

c. Rotate the HEPA filter to a new side and place it back into the carriage.

d. Latch the carriage lid.

e. Place the tongs away from the carriage motion.

f. Visually check the filter bag to see if it is full.

- If the filter bag is full, follow the filter bag removal and installation instructions in procedure III.

g. Signal the computer that the filter is ready for another side to be jointed (click on the start button).

h. Repeat step 2 for the remaining sides three and four.

3. After the fourth pass on the fourth side, the program will shut down the jointer/ vacuum system and ask the operator to rotate the filter. Operator will signal the computer, and then the program will terminate.

a. Open the carriage lid.

b. Lift the HEPA filter out of the carriage with the special tongs.

c. Inspect the HEPA filter for proper material removal.

d. Visually check the filter bag to see if it is full.

- If filter bag is full, follow filter bag removal and installation instructions in procedure III.

e. Signal the computer that the filter is ready for another side to be jointed. 


\section{Filter bag removal and installation procedure}

1. While the jointer is not operating, remove the inlet hose that has the slip fit connector located on top of the chip collector.

2. Unlatch the chip collector lid and pull the lid and bag out of the chip collector housing.

3. Slide the knurled ring off of the lid and remove the bag with the chips.

4. Close the bag and set it aside for chemical processing.

5. Put the knurled ring on the new filter bag.

6. Slide the knurled ring and the new filter bag onto the chip collector lid.

7. Make sure the O-ring is positioned in the groove, and line up the quarter-turn latches with the indents in the chip collector lid.

8. Insert the chip collector lid, knurled ring, and filter bag on top of the chip collector housing.

9. Line up the quarter-turn latches with the holes in the chip collector housing.

10. Push the latch knobs down and quarter turn.

11. Slide the inlet hose slip-fit hose back onto the chip collector lid.

\section{Blade change-out procedure}

1. Unplug and lockout the jointer motor.

2. Remove the belt guard covering the cutter assembly pulley.

3. Release the tension on the motor and remove the belt.

4. Unscrew the two bolts on both pillow blocks of the cutter assembly and remove the blade guards and bolts.

5. Slide the flat metal stock under both pillow blocks with the extra length of plate overhanging on the motor side.

NOTE: (The metal acts as a slide since the inside of the jointer housing is hollow, and the cutter assembly will fall in and jam without support.)

The nonpulley end of the cutter assembly may need to be lifted with a screwdriver to slide the metal plate under it.

6. Put a pair of heavy leather gloves over the glovebox gloves.

7. Remove the cutter assembly by sliding it towards the back (motor) side of the jointer.

8. Put the used cutter assembly in the disposal pack.

9. Make sure the jointer housing is clean before mounting a new cutter housing assembly.

10. Install the new cutter assembly in reverse order. 


\section{Use of vacuum pickup system}

1. Make sure that the coarse and fine bag filters are installed (change bag filters if required-see procedure III).

2. Disconnect the hose from the top of the coarse filter housing.

3. Attach the vacuum pickup hose to the top of the coarse filter housing.

4. Turn on the power to the vacuum blower.

\section{Computer Control of System}

The automation of the system is controlled by five relays in the computer. These 24-VDC (voltage direct current) relays control the higher voltage and high current relays in the NEMA enclosure.

In Table 1, the sequence of turning the relays on and off with time delays is shown. At step 0 , the jointer motor relay is turned on. This relay also turns on the carriage purge gas and the vacuum blower motor. There is then a 1-second delay for the motors to come up to speed. At step 1, the side air cylinder pushes the HEPA filter to the back of the carriage with a 1-second wait. At step 2, the top air cylinder pushes the HEPA filter flat onto the jointer table. There is a 1-second delay, and at step 3, the side air cylinder is turned off to prevent the tilting of the filter. At step 4, the linear actuator GO RETRACT terminal is pulsed to start the carriage moving into the cutting blades. GO RETRACT moves the carriage into the cutter blades, and GO EXTEND moves the carriage back to the starting position, because of the way the linear actuator is configured on the jointer base. The Hall-effect position sensors located on top of the linear actuator housing will automatically stop the linear actuator. At step 5, there is a 12-second wait while the carriage moves past the blades. At step 6, the top air cylinder is turned off and the side air cylinder is turned on so that the HEPA filter will not be pushed into the blades on the return pass. At step 7, the GO EXTEND terminal on the linear actuator is pulsed to move the carriage back to the starting position. At step 8, there is a 12-second wait while the carriage moves back. At step 9, the sequence is repeated three more times on the same side, since the depth of cut is currently set for $1 / 32$ inch and the total cut is $1 / 8$ inch. The filter is manually rotated at step 10 , and at step 11 the process is then repeated three more times, once for each HEPA filter side. 
Table 1. Control Sequence of System

\begin{tabular}{|c|c|c|c|c|c|c|c|}
\hline Step & $\begin{array}{c}\text { Timing } \\
\text { Delay(s) }\end{array}$ & $\begin{array}{c}\text { Jointer } \\
\text { Motor } \\
24 \text { VDC } \\
\end{array}$ & $\begin{array}{l}\text { Top Air } \\
\text { Cylinder } \\
24 \text { VDC }\end{array}$ & $\begin{array}{l}\text { Side Air } \\
\text { Cylinder } \\
24 \text { VDC } \\
\end{array}$ & $\begin{array}{c}\text { Carriage } \\
\text { Forward } \\
24 \text { VDC } \\
\end{array}$ & $\begin{array}{c}\text { Carriage } \\
\text { Back } \\
24 \text { VDC } \\
\end{array}$ & $\begin{array}{l}\text { Carriage } \\
\text { Position } \\
\end{array}$ \\
\hline 0 & & ON & OFF & OFF & OFF & OFF & Stop at start \\
\hline 1 & & ON & OFF & $\mathrm{ON}$ & OFF & $\mathrm{OFF}$ & \\
\hline 2 & 1 & ON & ON & ON & OFF & OFF & \\
\hline 3 & 1 & ON & ON & OFF & OFF & OFF & \\
\hline 4 & 1 & ON & ON & $\begin{array}{c}\text { OFF } \\
\text { THEN OFF }\end{array}$ & $\mathrm{ON}-$ & $\mathrm{OFF}$ & Forward/Stops \\
\hline 5 & 12 & ON & OFF & $\mathrm{ON}$ & OFF & OFF & Moving forward \\
\hline 6 & 1 & ON & OFF & ON & OFF & OFF & Stopped at end \\
\hline 7 & 1 & ON & OFF & ON & $\begin{array}{c}\text { OFF } \\
\text { THEN OFF }\end{array}$ & $\mathrm{ON}-$ & Returns/Stops \\
\hline 8 & 12 & $\mathrm{ON}$ & $\mathrm{OFF}$ & ON & OFF & OFF & Moving backward \\
\hline 9 & \multicolumn{7}{|c|}{ Repeat three more times on the same side } \\
\hline 10 & \multicolumn{7}{|c|}{ Rotate filter manually } \\
\hline 11 & \multicolumn{7}{|c|}{ Repeat three more times for each side } \\
\hline
\end{tabular}

This sequence is displayed on the LabView control panel screen during operation. Figure 2 shows a diagram of the control panel screen. The channel state at the bottom of the screen will display a green light when the specific relay is on and a red light when the relay is off. The SIDE \# counter will show which side of the HEPA filter is being processed, and the \# OF TIMES counter will show the number of the pass for each side. To start the program, click on the Start button with the computer mouse. The MOTOR light will turn green, and the jointer motor, vacuum blower motor, and gas purge will turn on. After the delay, the top cylinder light will become green, and the cylinder will push the HEPA filter down on the table. The rest of the sequence is followed as shown in Table 1. After one side of the filter is done, the program will ask the operator to manually rotate the filter and then begin the sequence again.

NOTE: Since the program is not receiving feedback pertaining to the position of the linear actuator, if the process is stopped with the emergency stop button, the program should be stopped and reset before the emergency button is reset. This will prevent the program from moving the carriage into the rail stops. 


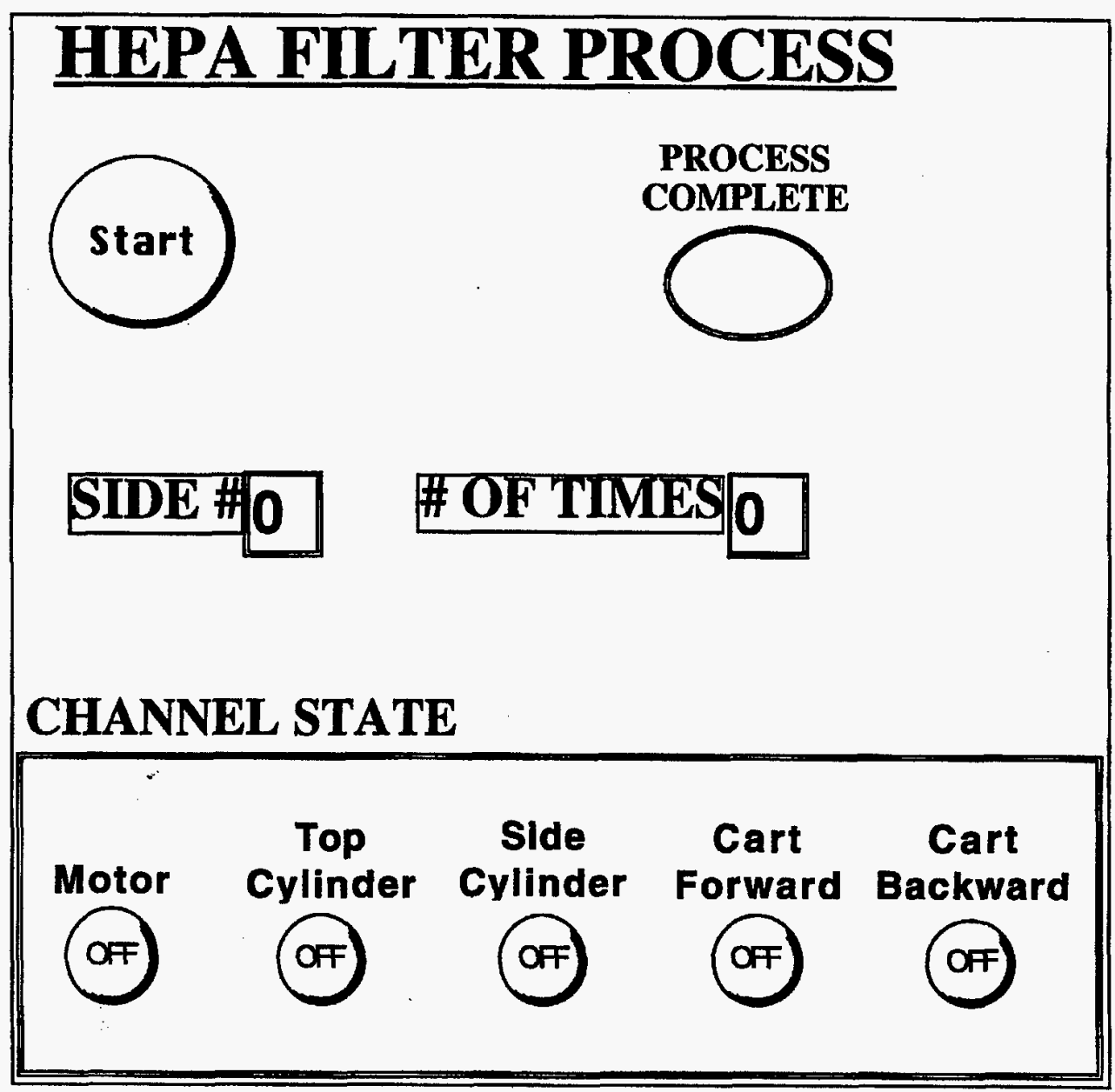

Figure 2. LabView control panel screen.

\section{Electronics}

The automation of the system is controlled with five relays. Three relays control the solenoids that allow gas flow to the purge line, side air cylinder, and top air cylinder. The other two relays control the forward, GO RETRACT, and return, GO EXTEND, movement of the cart. Note that GO RETRACT and GO EXTEND are relative to the side of the linear actuator where the DC motor is located. Because the initial position of the cart is on the right side of the linear actuator and the motor is on the left side, GO RETRACT moves the carriage forward, and GO EXTEND moves the carriage back to the original position. The STOP function on the motor controller is wired into the relay card but is not used in the program.

Figure 3 shows the wiring for the computer control of the air solenoids. Inside the computer relay card, $24 \mathrm{VDC}$ is used instead of $120 \mathrm{VAC}$ to reduce AC noise and high voltages inside the computer. The computer switches the 24 VDC which switches the 
solid-state relays. The relays, in turn, send $120 \mathrm{VAC}$ to the solenoids. The solenoids control the gas flow to the purge line and air cylinders. The motor starter and vacuum blower relay are also turned on when the purge solenoid is turned on. The jointer motor starter is both a relay and a thermal fuse for the 480-VAC three-phase power supply to the $1.5 \mathrm{HP}$ jointer motor. The vacuum blower relay is switched by 24 VDC.

Figure 4 shows the wiring for the computer control of the linear actuator. When the GO RETRACT terminal is grounded to COMMON in the computer relay card, the carriage moves forward until the end-of-travel Hall-effect sensor on the top of the linear actuator

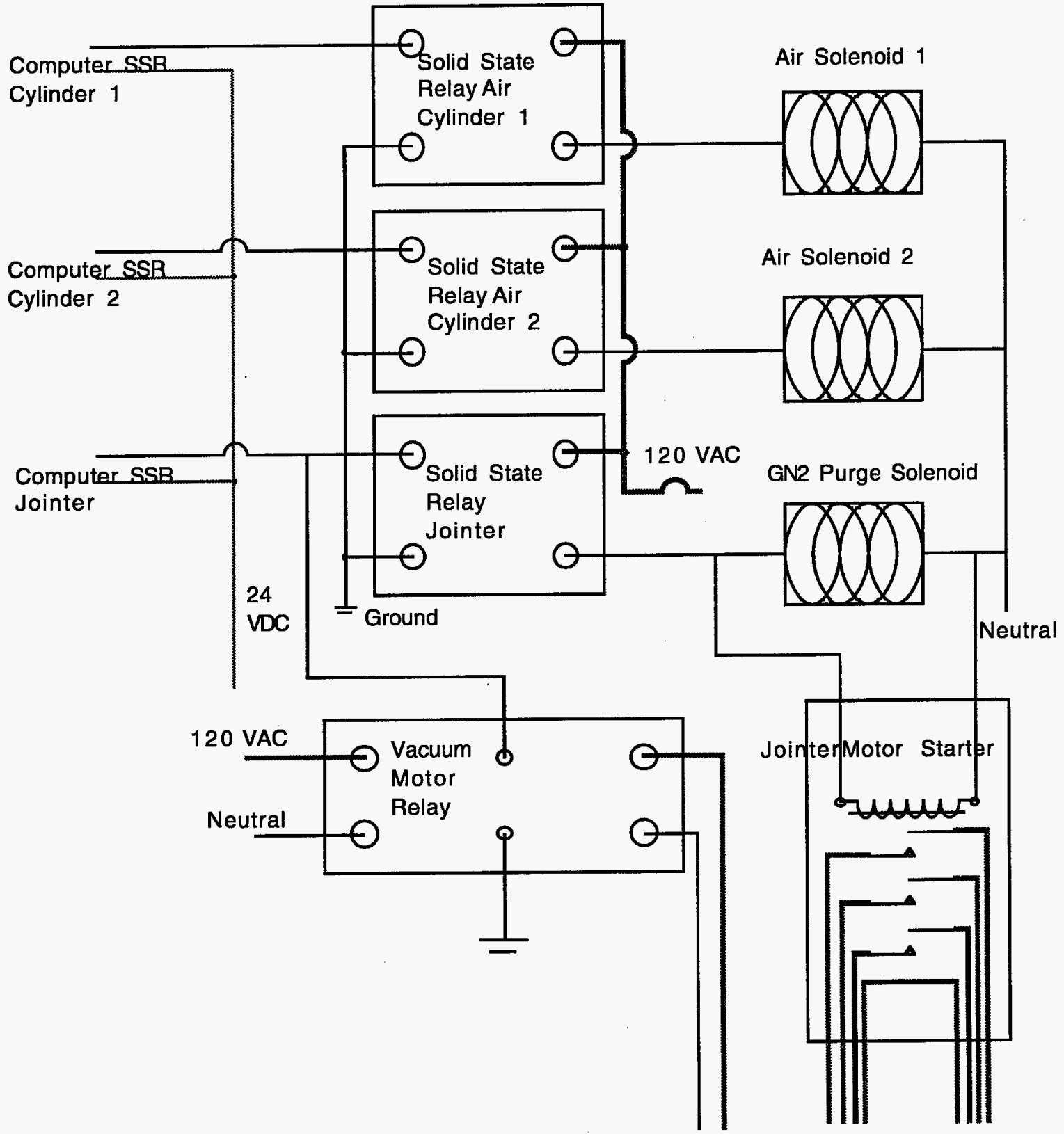

Figure 3. Wiring for the computer control of the air solenoids. 
stops the forward motion. After a time delay, the computer will close a relay, and the GO EXTEND terminal is grounded to the COMMON and the carriage will move back to the other end-of-travel sensor. The end-of-travel switches can be moved along the rail on top of the linear actuator to change the stopping positions of the carriage. When the switch on the remote control is in the jog position, the carriage can be moved back and forth by holding down the reverse and forward buttons. When the switch on the remote control is in the run position, a momentary close of the reverse and forward buttons will move the carriage to one of the end-of-travel switches. A momentary close of the stop button will always stop the movement of the carriage. An emergency stop button is also mounted on the remote control box. When this button is pushed in, the whole system will shut down.

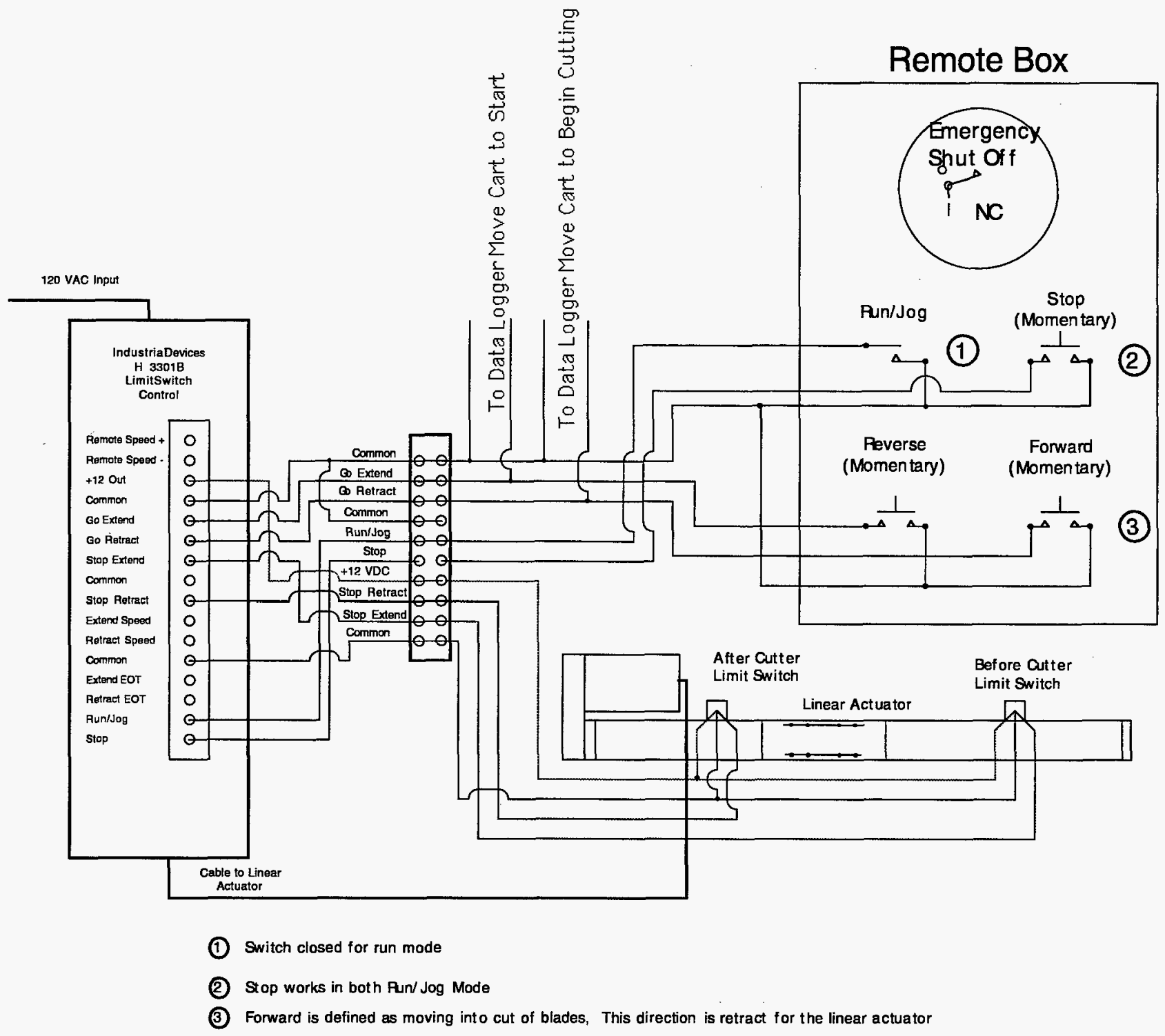

Figure 4. Wiring for the computer and remote box control of the linear actuator. 
In Figure 5, the wiring for the shutdown of the system is shown. To shut the system down, the 24 VDC power to the computer card must be turned off, and the STOP terminal on the linear actuator must be grounded. These two lines are run through the emergency shutoff and interlock relay. The remote box emergency stop button, light curtain relay, and interlock switch on the carriage are wired in series and power the relay. When one of these devices opens, the relay will open and stop the carriage and terminate power to the computer card. The light curtain relay is not connected, but an extra terminal is located in the NEMA enclosure for adding the wires.

Tables 2, 3, and 4 list the wire colors for the relay card, remote box, and solenoid box wiring, respectively. Table 1 also shows which device each channel, in the relay card and program, controls. These tables are helpful when troubleshooting electrical problems.

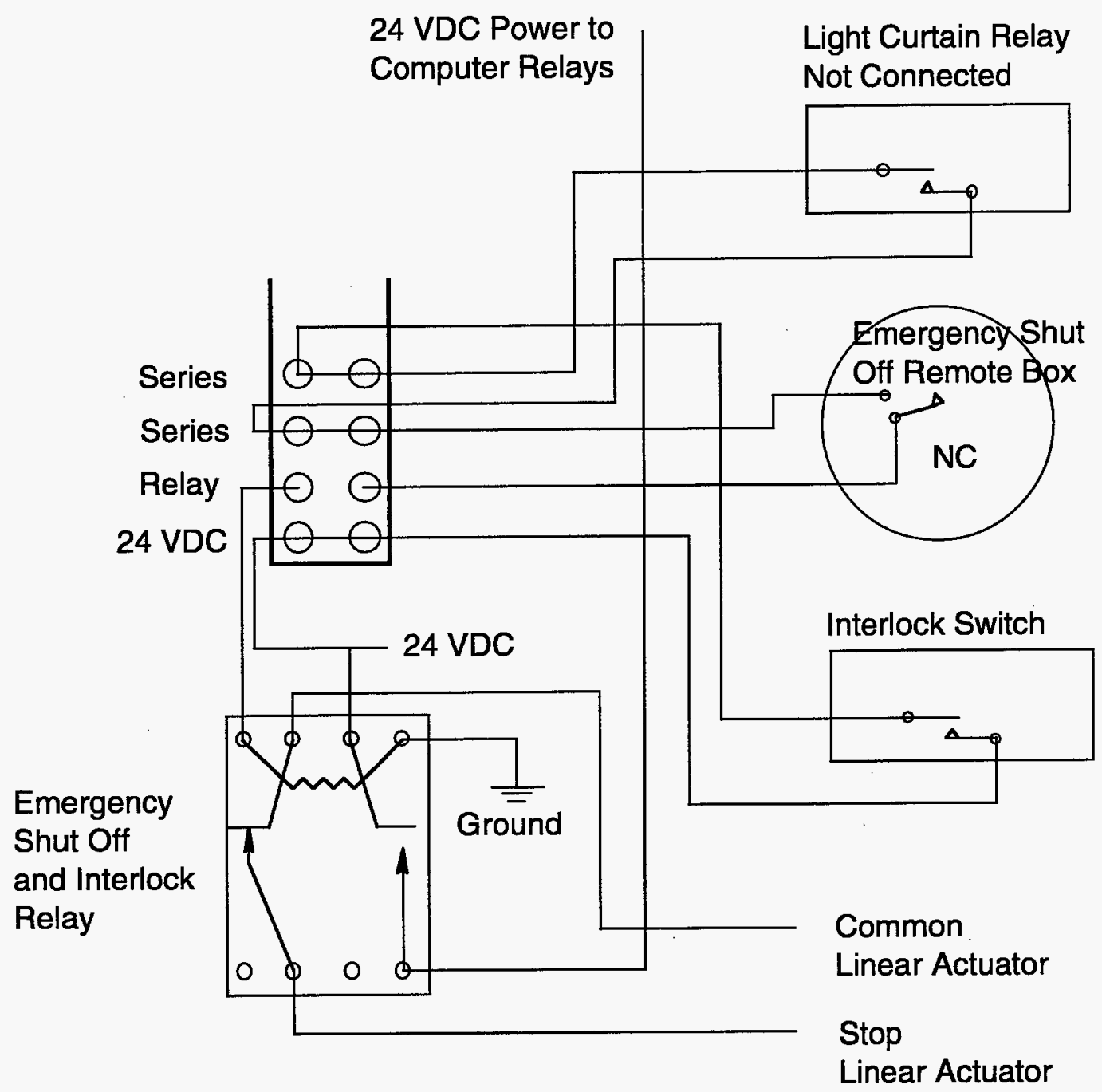

Figure 5. Wiring for the shutdown of the system. 


\begin{tabular}{clcl}
\multicolumn{3}{c}{ Table 2. Data Logger Relay } & \multicolumn{2}{l}{ Card Wiring } \\
\hline Channel & \multicolumn{1}{c}{ Device } & Relay & Wire Color \\
\hline 0 & Jointer & NO & Blue \\
1 & Cylinder 2 (side) & NO & Orange \\
2 & Cylinder 1 ( top) & NO & White \\
3 & GO RETRACT & NO & Green \\
4 & GO EXTEND & NO & Brown \\
5 & RUN/JOG & NC & Not connected \\
6 & STOP & NO & Yellow \\
& Common & & Black \\
& 24 VDC & & Red \\
\hline
\end{tabular}

Table 3. Remote Box Wiring

\begin{tabular}{ll}
\hline Button & Wire Color \\
\hline GO EXTEND & Brown \\
GO RETRACT & Green \\
STOP & Yellow \\
RUN/JOG & Blue \\
Common & Black \\
Emergency Stop & Orange \\
Wires & White \\
\hline \hline
\end{tabular}

Table 4. Solenoid Box Wiring

\begin{tabular}{ll} 
Solenoid & Wire Color \\
\hline Purge & Blue \\
Cylinder 1 (Top) & Orange \\
Cylinder 2 (Side) & Red \\
Neutral & White \\
Ground & Green \\
\hline
\end{tabular}

\section{Wiring of NEMA enclosure}

Three NEMA enclosures house the electronic components. One enclosure contains the air solenoids, and another contains switches for moving the carriage and emergency stop button. The main NEMA enclosure, shown in Figure 6, contains the high-voltage and current relays, the motor driver, the emergency stop circuit, and the electronics that support these.

Figure 7 shows the wiring diagram of the NEMA enclosure. The three subsystemsmotor controller, shutdown system, and air solenoid control-are in this drawing. All of the $120 \mathrm{VAC}$ power for the system, except for the computer, comes from this box. The power is run through a fuse located on the door and then through a $30 \mathrm{amp}$ relay. The relay is actuated by 28 -VAC controlled by the emergency stop button on the door. After the relay, the power is run through a filter and then three individual fuses. One fuse limits the current going into the vacuum blower. The power to the vacuum blower is controlled by a $20 \mathrm{amp}$ relay which is controlled by a $120 \mathrm{VAC}$ solid-state relay which 
is, in turn, controlled by the 24 VDC power from the computer relay. A separate switch on the door can be used to turn on the vacuum blower.

The 480 VAC three-phase motor starter in a NEMA box is attached to the side of the big NEMA enclosure. This motor starter contains the relays and thermal fuses to provide power to the jointer motor.

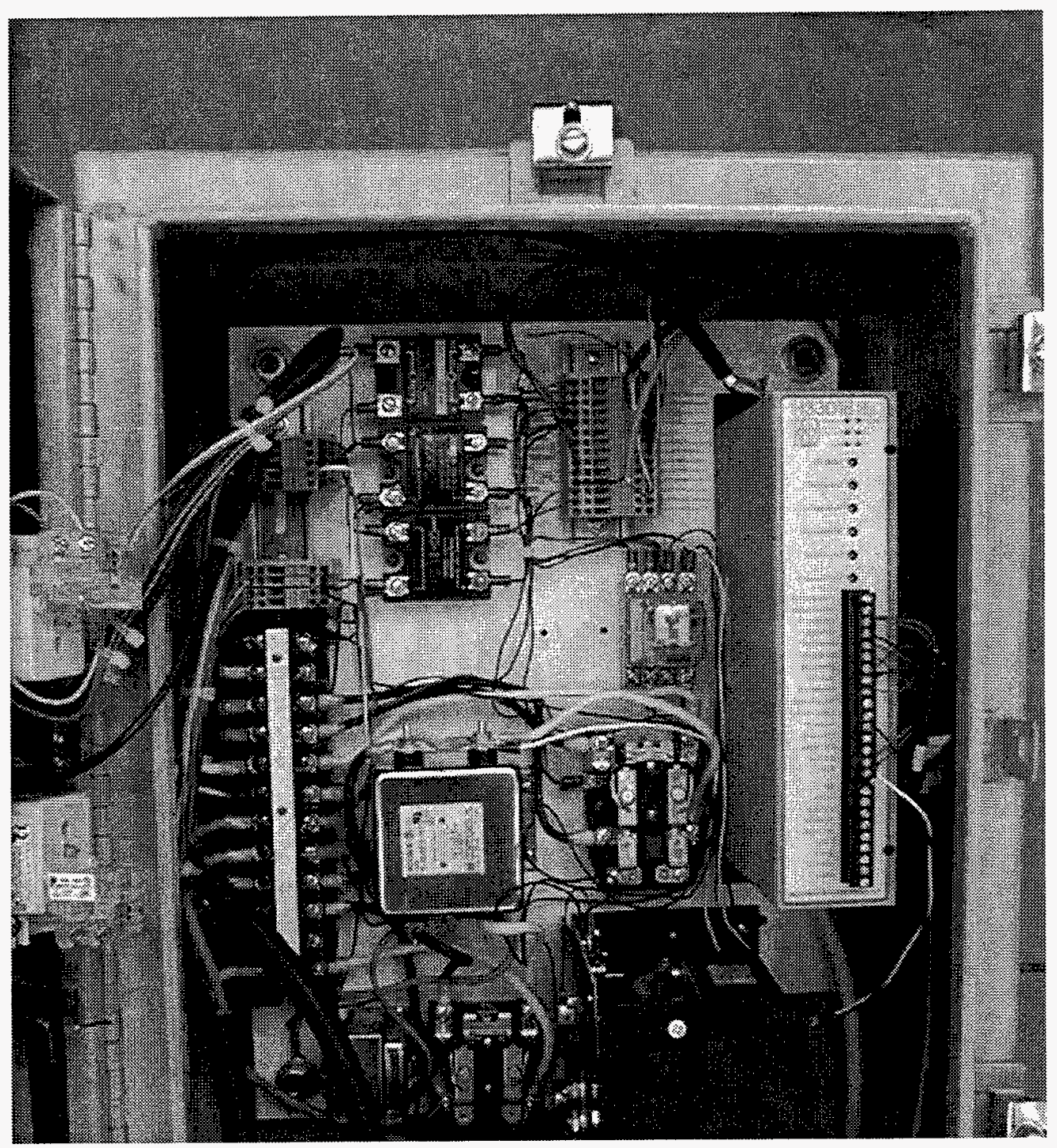

Figure 6. NEMA enclosure with electronics. 


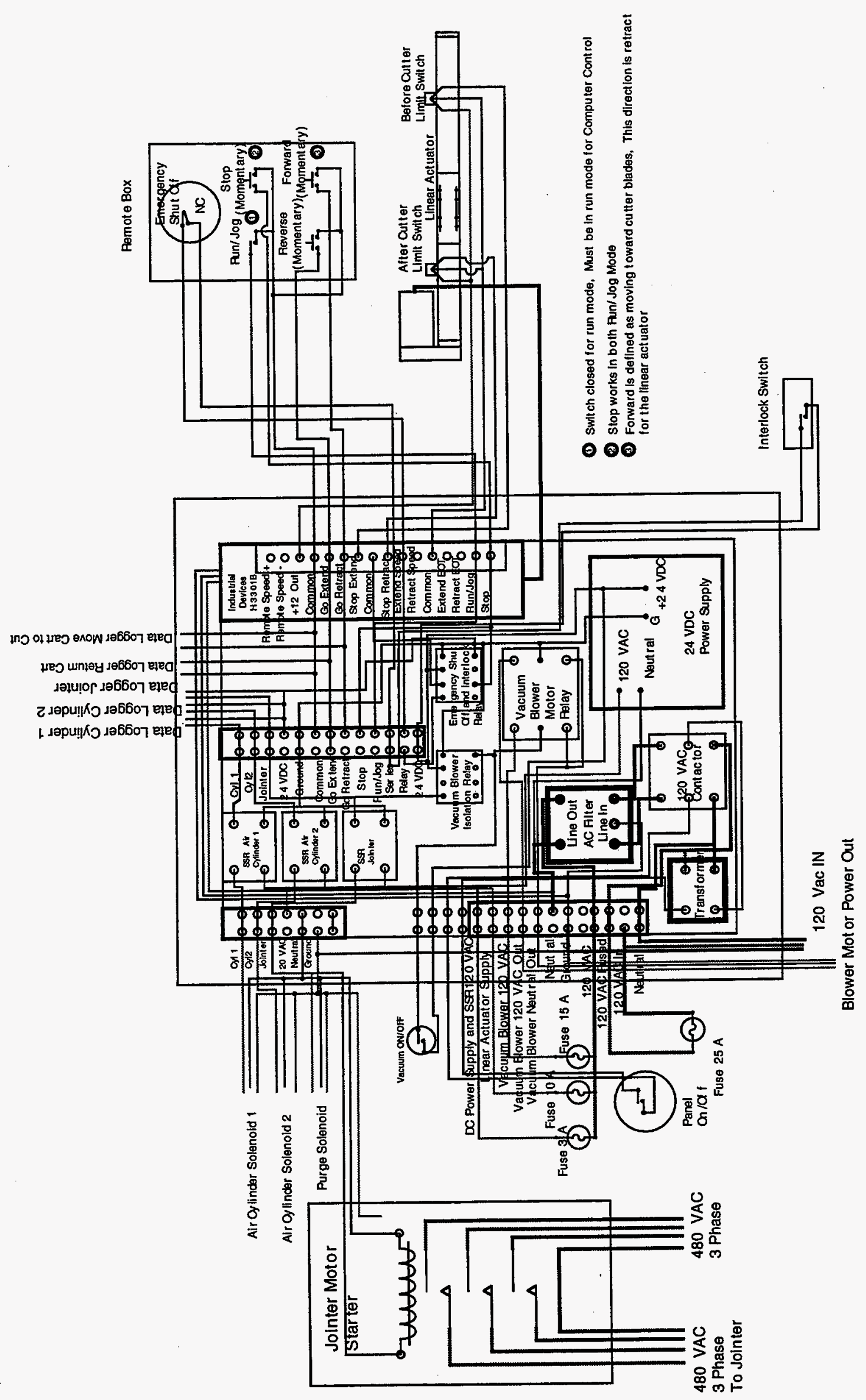

Figure 7. Wiring diagram of electronics in NEMA enclosure. 


\section{Blade Setup Procedure}

The cutterhead assembly height from the factory can vary as much as 0.015 inch. Since it is difficult to change the height of the out table because the adjustment is behind the $480 \mathrm{~V}$ motor, it is simpler to raise the blades in the cutterhead assembly to a standard value. The geometry of the cutterhead assembly and jointer tables is shown in Figure 8. A standard value of 3.487 inches from the base of the bearing block to the top of the cutter blade is reasonable. This will put the blade height 0.005 inch above the out table, as recommended by Delta. The manufacturer recommends setting the blades 0.020 inch above the spindle, so this procedure will increase this distance a few thousandths. The in table is much easier to adjust in the glovebox if the depth of cut needs to be changed. From the depth of cut tests, it appears that the in table should be set at the depth of the desired cut less 0.005 inch.

\section{1/27/96 Endurance Test}

The Delta Jointer DJ20 was endurance tested with fire retardant 3/4 inch plywood (five layers) and 3/4 inch particle board. Sheets of $4 \mathrm{ft} \times 8 \mathrm{ft}$ plywood and particle board were cut into 6 in. $\times 8 \mathrm{ft}$ strips. These strips were run through the jointer. The jointer was set for a 1/16-inch-deep cut, and two passes were made on both sides of the strips of wood. This resulted in an amount of material equivalent to 24 plywood filters and 24 particle board filters. The carbide blades were photographed under a microscope before and after the test was performed. Figure 9 shows a picture taken at $100 \times$ of the edge of a jointer blade before the endurance test. Figure 10 shows a picture taken at $100 \times$ of the edge of the jointer blade after the endurance test. The photographs show that the edge of the blade is severely worn. The width of the lighted section of the blade in Figure 10 is 0.002 inch.

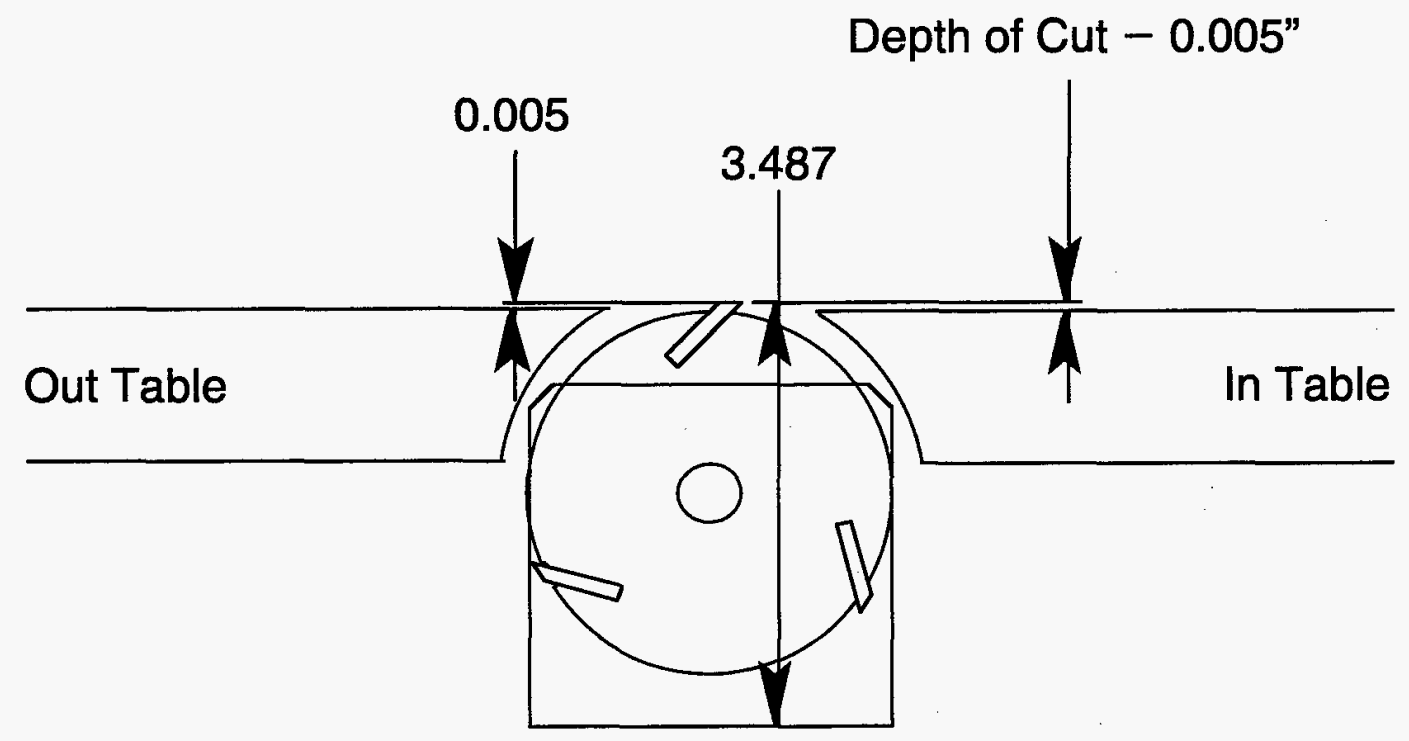

Figure 8. Geometry of cutterhead and tables. 


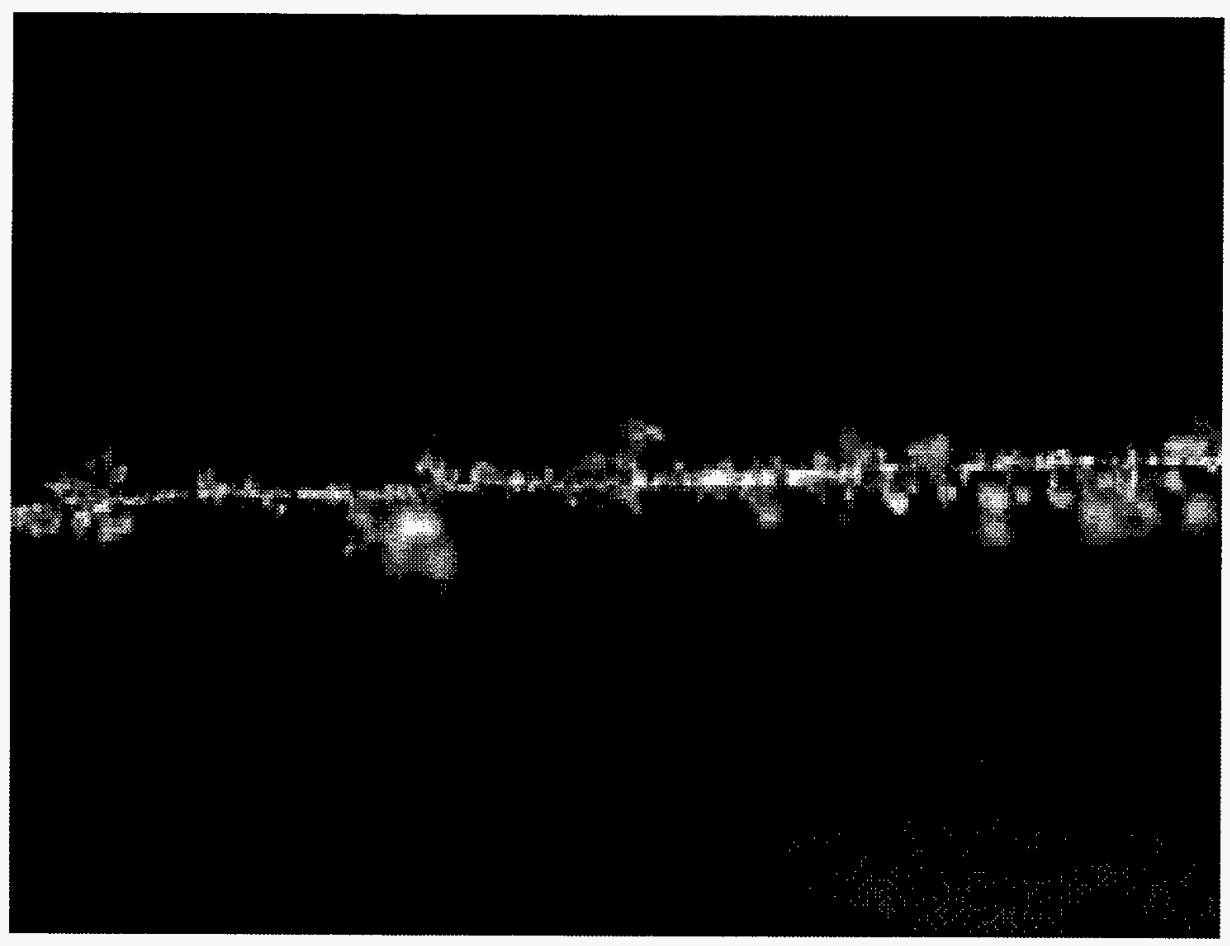

Figure 9. Sharp jointer blade edge before endurance test $(100 \times)$.

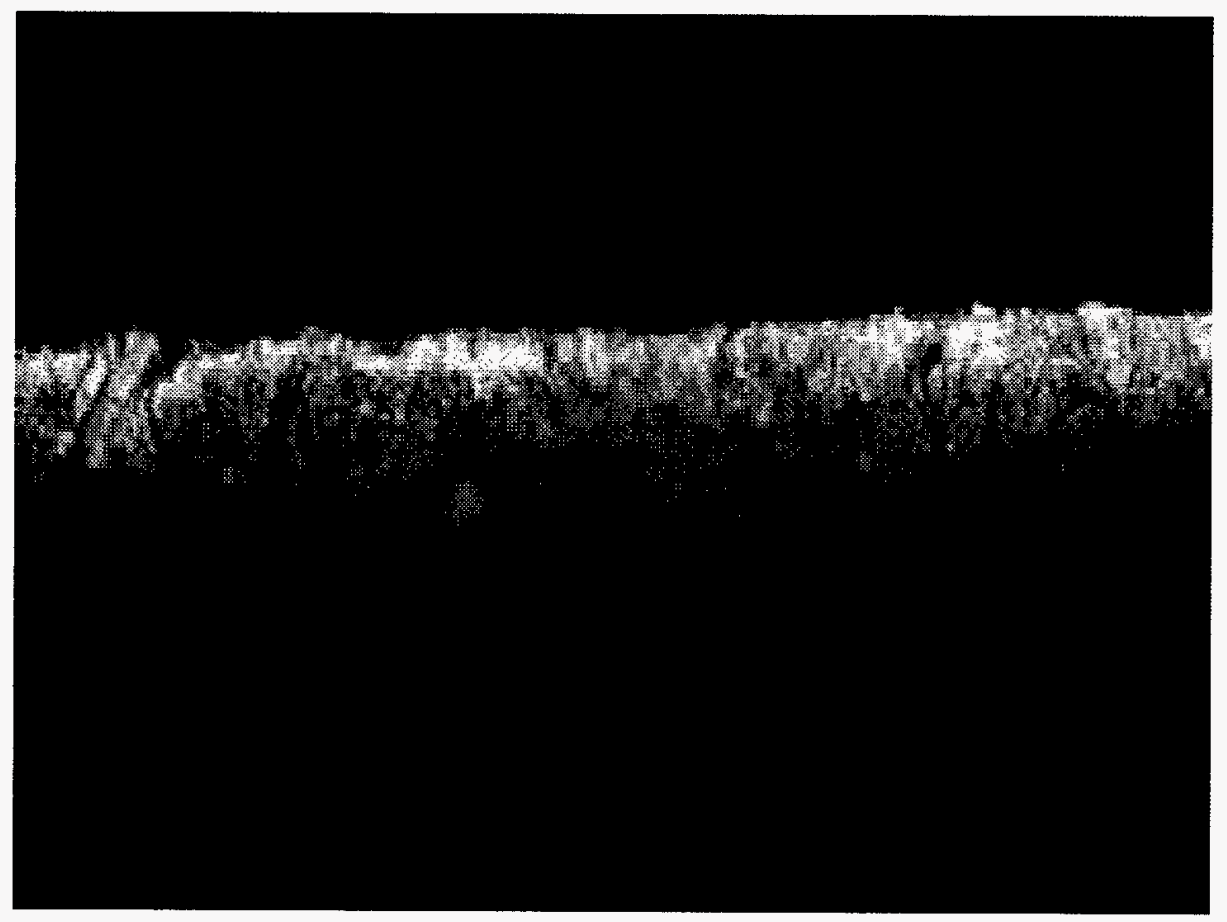

Figure 10. Jointer blade edge after endurance test (100x). 
The plywood did not wear the blades a noticeable amount, but the particle board did dull the blades. Apparently, particle board is made of trees and tree roots that sometimes have rocks in them that get crushed up into the particle board sheets. The dull blades were reground and are now cutting well. The endurance test also showed that there is a volume increase of 3.6 times for plywood and 2.8 times for particle board. Figure 11 shows the particle size distribution for both the particle board and plywood chips. The majority of both types of chips were in the 60-mesh size range. As shown in the figure, the particle board produces finer chips than the plywood does.

\section{Filter Depth of Cut Test 10/30/97}

Filter frames were made out of 3/4 inch plywood and cut on the jointer to determine the quality of the material removal. In Figure 12 the setup of the blades and table is shown. For this test, the out table was set to the same height as the cutting blades. No difference was observed when compared to having the out table set 0.005 inch lower than the blades. The in table was set to 0.027 inch below the blades, since previous tests have shown that the in table should be set 0.005 inch less than the desired depth of cut. However, it was later found that the optimum setting is closer to 0.003 inch less than the desired depth of cut.

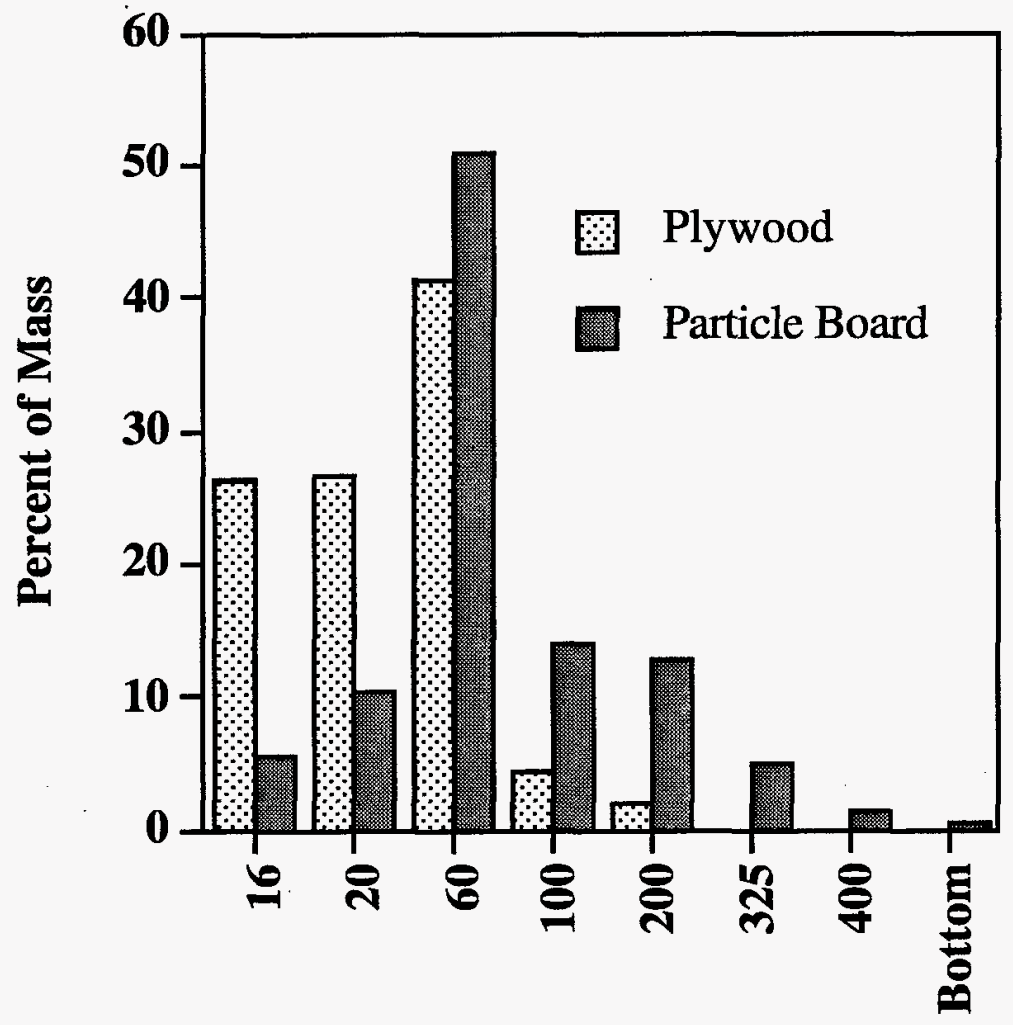

Mesh Size

Figure 11. Particle size of wood chips from jointer operation. 


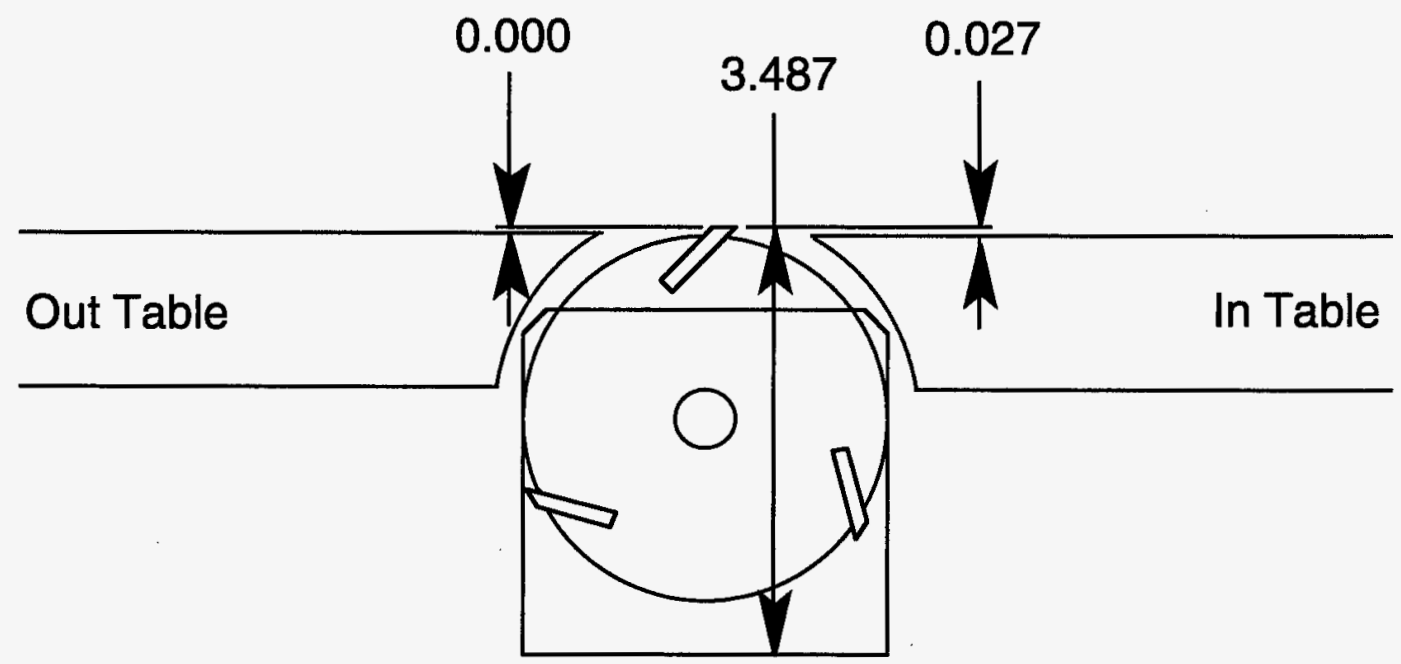

Figure 12. Geometry of blades during the depth of cut test.

Table 5 shows the depth of cut data for the filter frames when the top air cylinder is set in the middle of the frame, the front air cylinder is turned on during the forward pass, and there is no shim at the base of the back plate in the carriage. The depth of cut was measured at six places on a side and then averaged. The average depth of slope was

Table 5. Depth of cut data without a shim at the back of the carriage and with the air cylinder set in the middle of the filter

\begin{tabular}{cccc}
\hline $\begin{array}{c}\text { Filter } \\
\text { Number }\end{array}$ & $\begin{array}{c}\text { Side } \\
\text { Number }\end{array}$ & $\begin{array}{c}\text { Average Depth } \\
\text { of Cut (inches) }\end{array}$ & $\begin{array}{c}\text { Average Depth } \\
\text { of Slope (inches) }\end{array}$ \\
\hline 1 & 1 & 0.141 & 0.024 \\
1 & 2 & 0.140 & 0.012 \\
1 & 3 & 0.133 & 0.040 \\
1 & 4 & 0.139 & 0.028 \\
2 & 1 & 0.141 & 0.028 \\
2 & 2 & 0.126 & 0.058 \\
2 & 3 & 0.143 & 0.026 \\
2 & 4 & 0.133 & 0.047 \\
3 & 1 & 0.134 & 0.038 \\
3 & 2 & 0.125 & 0.044 \\
3 & 3 & 0.124 & 0.018 \\
3 & 4 & 0.121 & 0.060 \\
\hline
\end{tabular}


determined by finding the average difference between the measured cuts at the front and back of the filter. The actual numbers and measurement locations used to determine the average for each side are shown in the appendix.

While jointing the filter frames shown in Table 5, we noticed that the filter frames had a significant slope to the cut (cutting deeper on the front side than the back side). For these three filters, the average depth of cut was 0.133 inch and the average depth of slope was 0.035 inch. This slope depth of 0.035 inch means that the front of the filter was cut 0.035 inch deeper than the back of the filter. That seemed high, so we proceeded to try to reduce this slope depth.

It was noticed that the filter would rock in the carriage when the front air cylinder pushed on it. The carriage back was just a few thousands of an inch from being perpendicular to the in table, which allowed the back of the filter to lift slightly, resulting in a

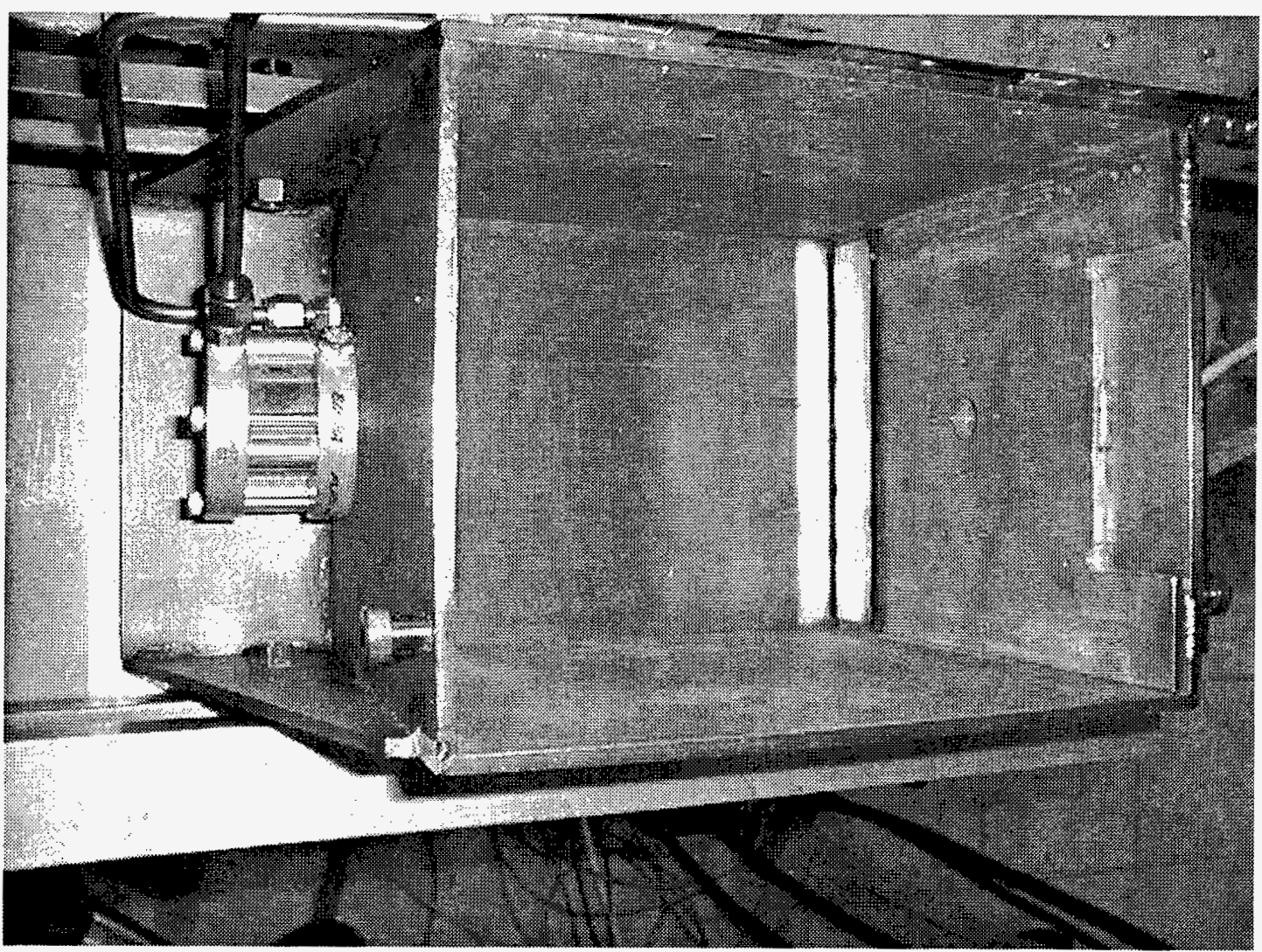

Figure 13. The shim is visible at the lower back edge of the carriage. 
shallower cut at the back of the filter. To correct the problem, a shim, shown in Figure 13 , was welded at the lower back plate, and the front air cylinder was turned off during the forward pass of the carriage. The shim, at the lower back edge of the carriage, appears shiny in the picture.

Table 6 shows the depth of cut data when the air cylinder on the top of the filter was moved to the back end of the filter frame, the front air cylinder is not used during the forward path, and the shim is placed on the back end of the carriage. The filters cut with this configuration show that the back of the filter was cut 0.021 inch deeper than at the front. The overall depth of cut was 0.107 inch for this configuration.

Table 7 shows depth of cut data when the air cylinder on the top of the filter was centered over the filter frame, the front air cylinder is not used during the forward path, and the shim is placed at the back of the carriage. The filters cut with this configuration show that, on the average, the front of the filter was cut 0.015 inch deeper than the back. The overall depth of cut was 0.117 inch for this configuration, which means that the in table should be set 0.029 inch below the blades to get an average depth of cut of 0.125 inch for the four passes. Some of the higher numbers in the depth of slope are due to the jointer making the cross cut at the corners of the frame, causing the wood to sometimes bend back and not shear off of the back of the frame resulting in a fuzzy texture of raised wood fibers that spring back. The wood at the front of the frame will cut, since there is wood behind it that provides support for cutting. This results in the back of the filter being lifted for the next pass. This.fuzz problem was noticed for filter four, side two, and filter five, side four.

Table 6. Depth of cut data with a shim at the back of the carriage and the top air cylinder set at the back of the filter

\begin{tabular}{|c|c|c|c|}
\hline $\begin{array}{c}\text { Filter } \\
\text { Number }\end{array}$ & $\begin{array}{c}\text { Side } \\
\text { Number }\end{array}$ & $\begin{array}{l}\text { Average Depth } \\
\text { of Cut (inches) }\end{array}$ & $\begin{array}{c}\text { Average Depth } \\
\text { of Slope (inches) }\end{array}$ \\
\hline 7 & 1 & 0.103 & -0.035 \\
\hline 7 & 2 & 0.097 & -0.043 \\
\hline 7 & 3 & 0.091 & -0.052 \\
\hline 7 & 4 & 0.110 & -0.010 \\
\hline 10 & 1 & 0.117 & 0.002 \\
\hline 10 & 2 & 0.116 & -0.002 \\
\hline 10 & 3 & 0.107 & -0.017 \\
\hline \multirow[t]{2}{*}{10} & 4 & 0.112 & -0.011 \\
\hline & Average & 0.107 & -0.021 \\
\hline
\end{tabular}


Table 7. Depth of cut data without a shim at the back of the carriage and with the air cylinder set in the middle of the filter

\begin{tabular}{cccc}
\hline $\begin{array}{c}\text { Filter } \\
\text { Number }\end{array}$ & $\begin{array}{c}\text { Side } \\
\text { Number }\end{array}$ & $\begin{array}{c}\text { Average Depth } \\
\text { of Cut (inches) }\end{array}$ & $\begin{array}{c}\text { Average Depth } \\
\text { of Slope (inches) }\end{array}$ \\
\hline 4 & 1 & 0.123 & 0.005 \\
4 & 2 & 0.115 & 0.037 \\
4 & 3 & 0.128 & 0.006 \\
4 & 4 & 0.122 & 0.010 \\
5 & 1 & 0.114 & 0.021 \\
5 & 2 & 0.118 & 0.020 \\
5 & 3 & 0.118 & 0.005 \\
5 & 4 & 0.115 & 0.028 \\
6 & 1 & 0.120 & 0.016 \\
6 & 2 & 0.100 & -0.010 \\
6 & 3 & 0.124 & 0.011 \\
6 & 4 & 0.119 & 0.018 \\
8 & 1 & 0.110 & 0.012 \\
8 & 2 & 0.108 & 0.009 \\
8 & 3 & 0.119 & 0.007 \\
8 & 4 & 0.117 & 0.023 \\
9 & 1 & 0.119 & 0.020 \\
9 & 2 & 0.117 & 0.024 \\
9 & 3 & 0.117 & 0.013 \\
9 & 4 & 0.110 & 0.034 \\
\hline & Average & 0.117 & 0.015 \\
\hline
\end{tabular}

\section{Conclusions}

After these filter frames were jointed, some changes were made to the system to improve the quality of the cuts. A shim was added to the lower back edge of the carriage so that the filter will sit flat on the in feed table during cutting. The front air cylinder is no longer used on the forward pass. The front air cylinder is used to push the filter against the back of the carriage before the forward pass and on the return pass to lift the filter frame above the blades. 
Appendix 
Front

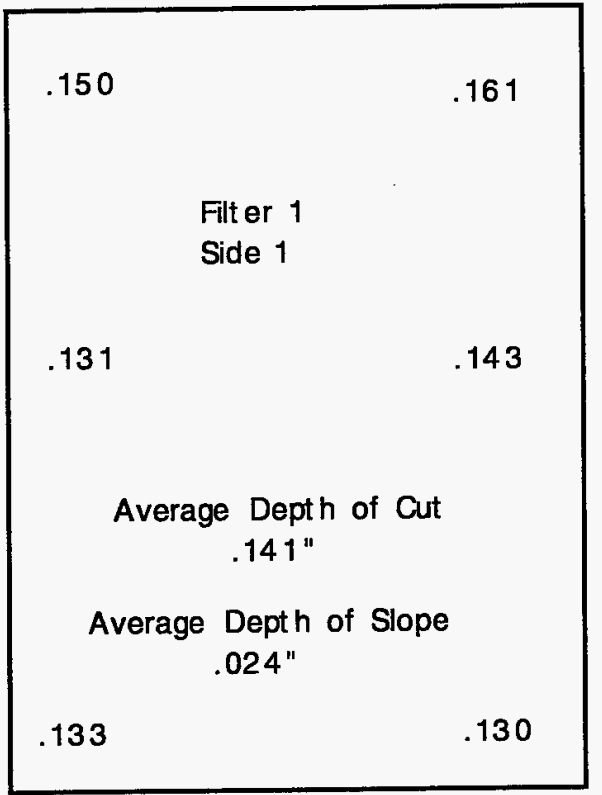

Back

Front

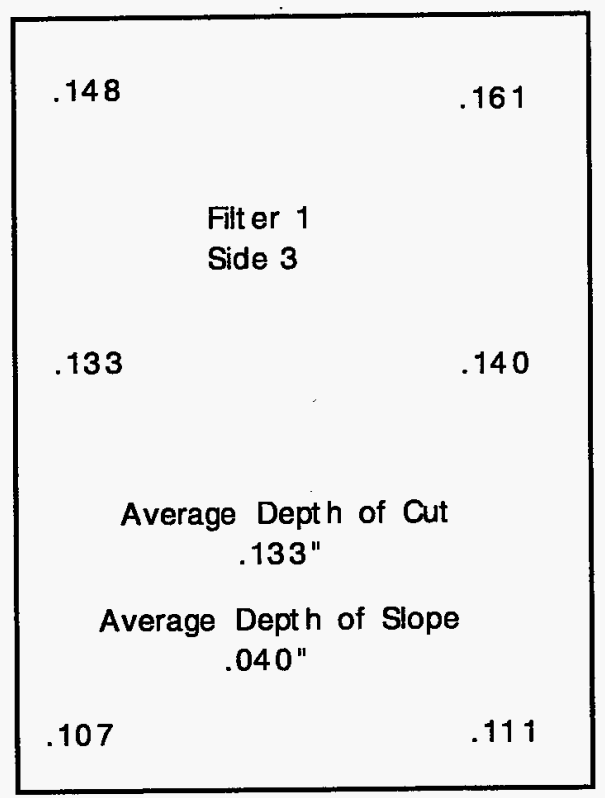

Back
Front

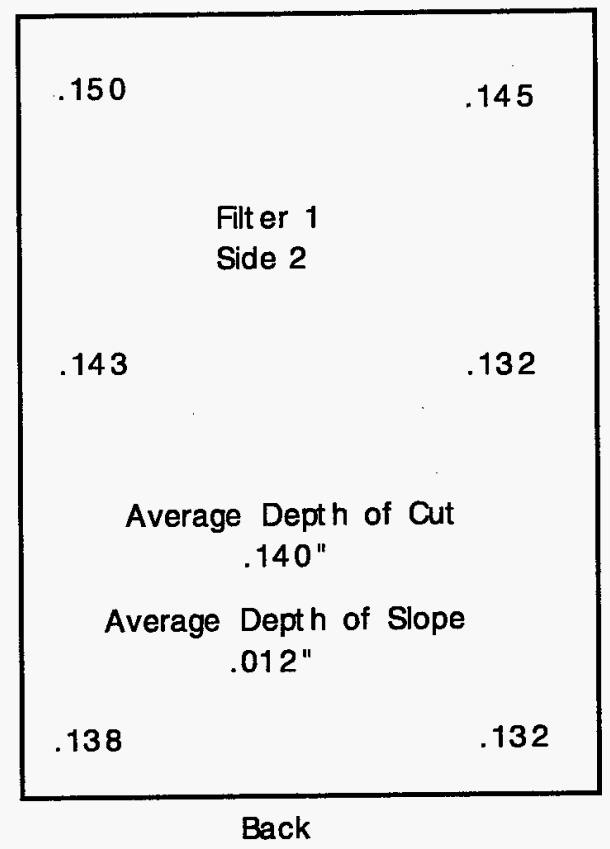

Front

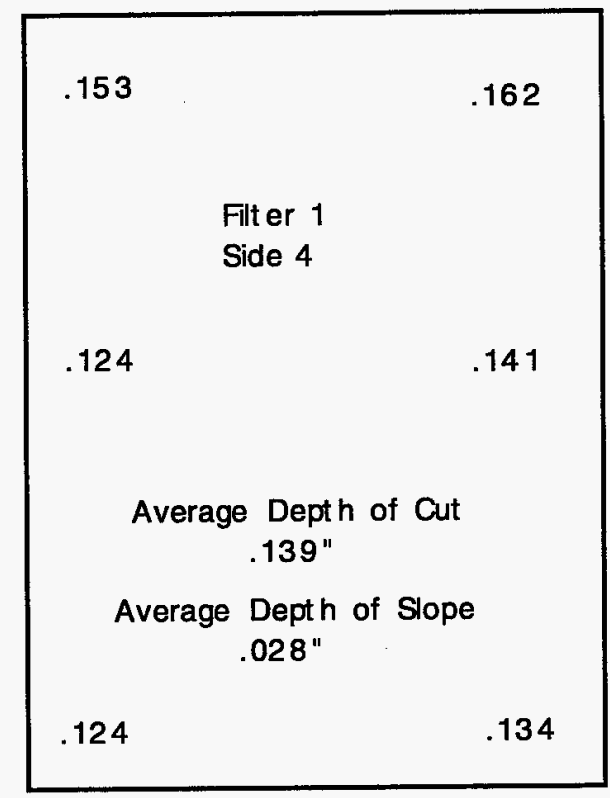

Back 
Front

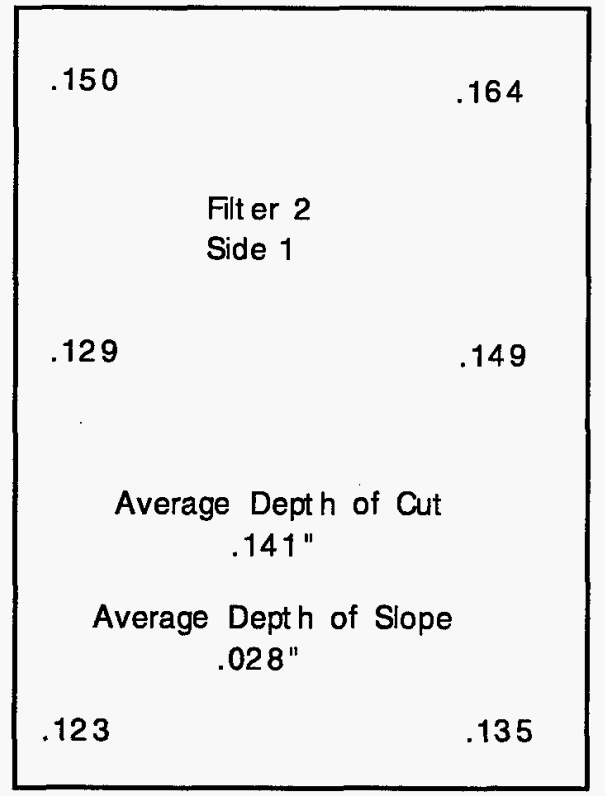

Back

Front

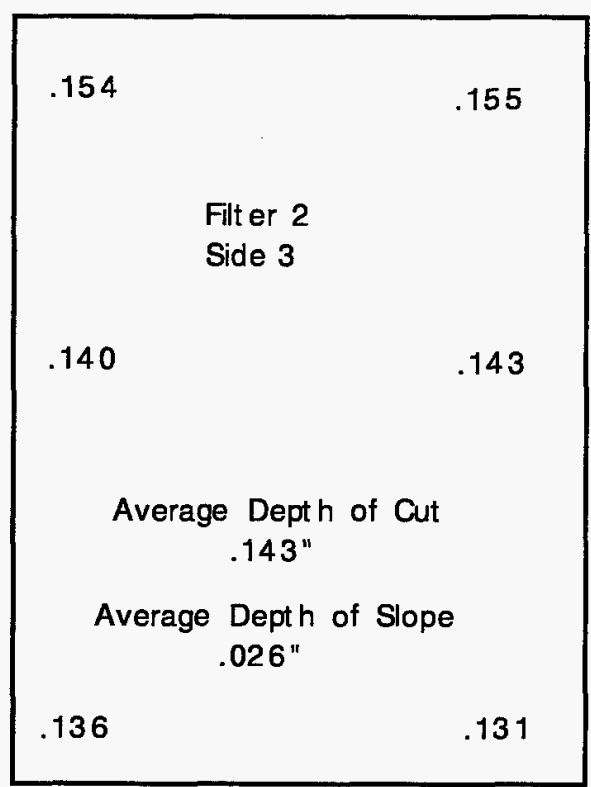

Back
Front

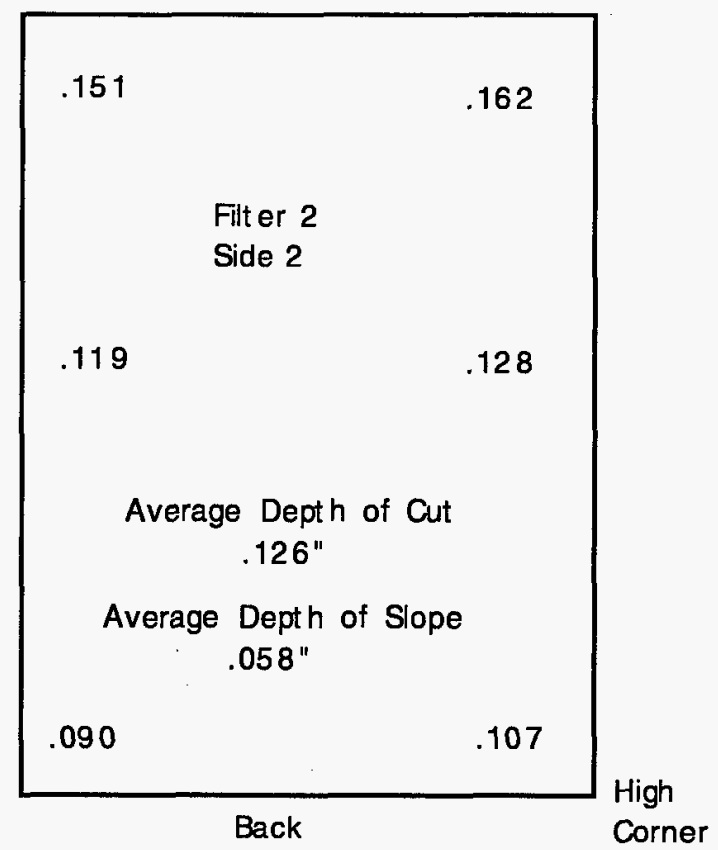

Front

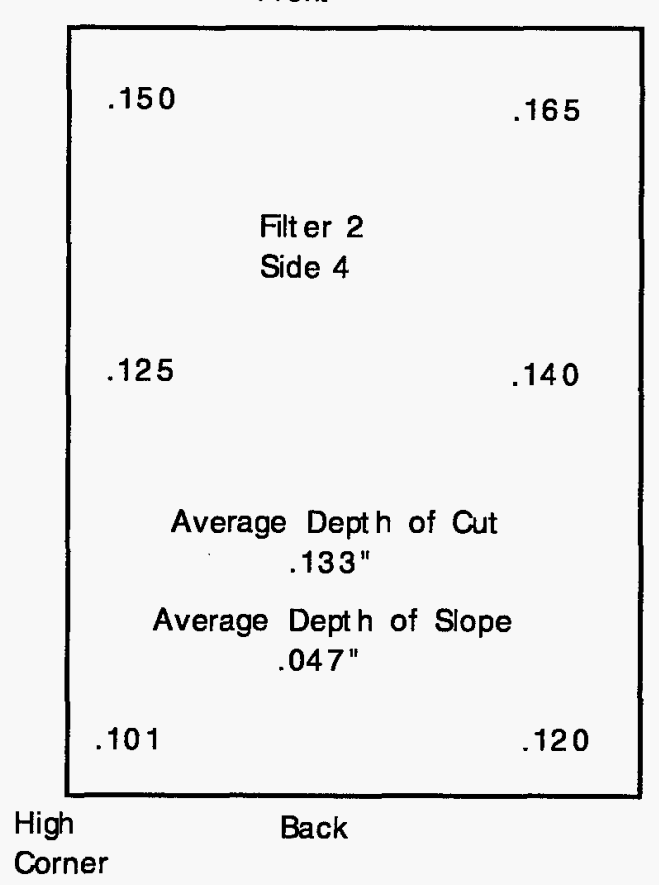


Front

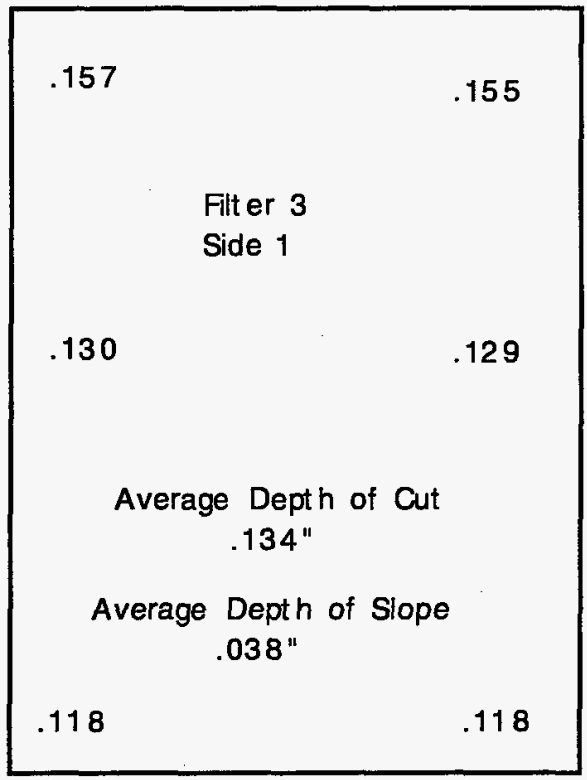

Back

Front

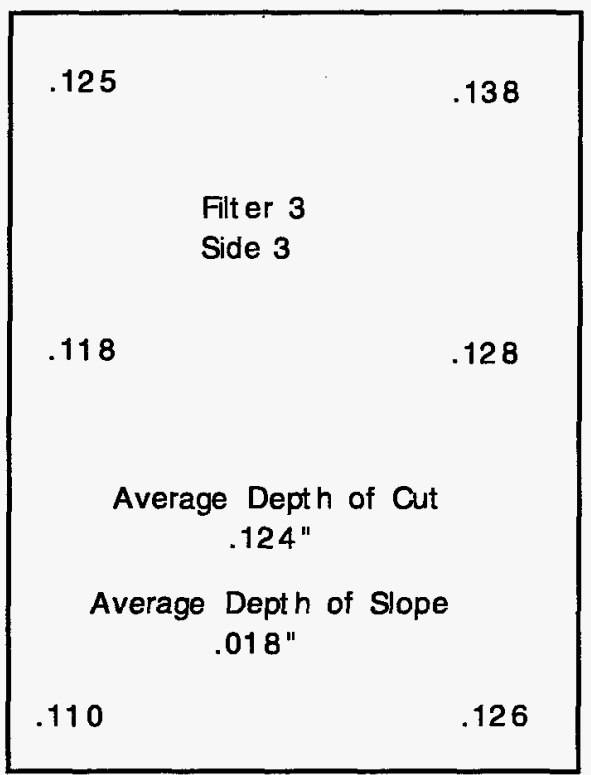

Back
Front

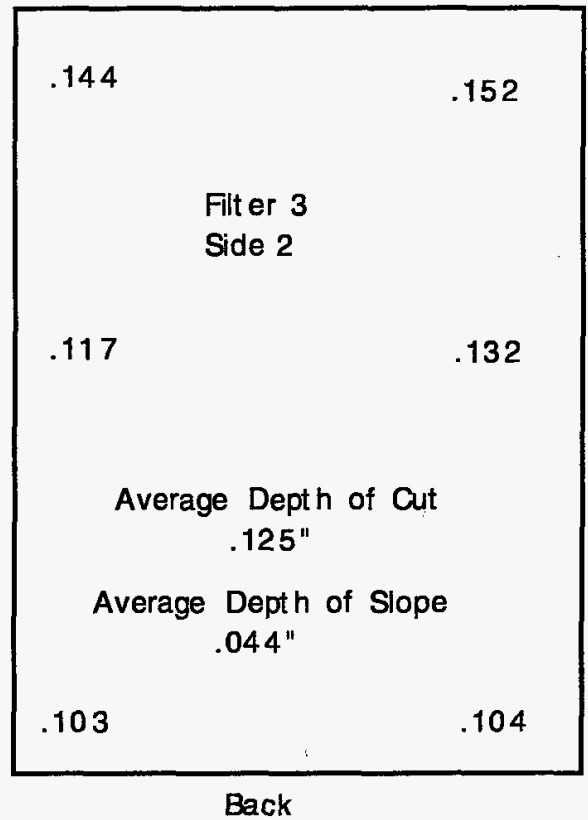

Front

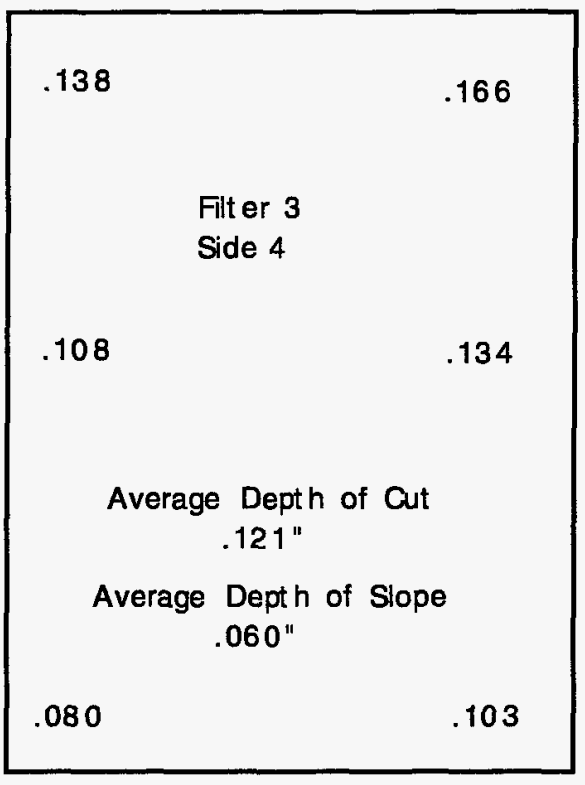

Back

Big splinters from cross cut 
Front

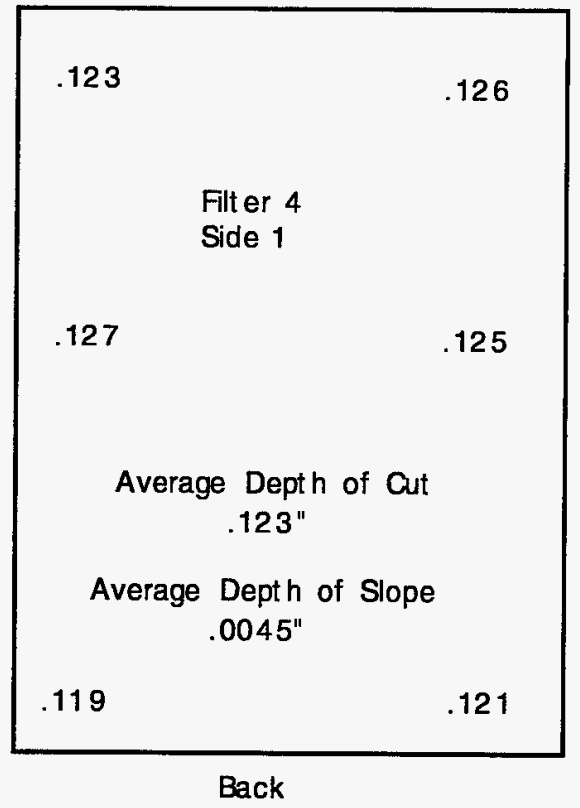

Front

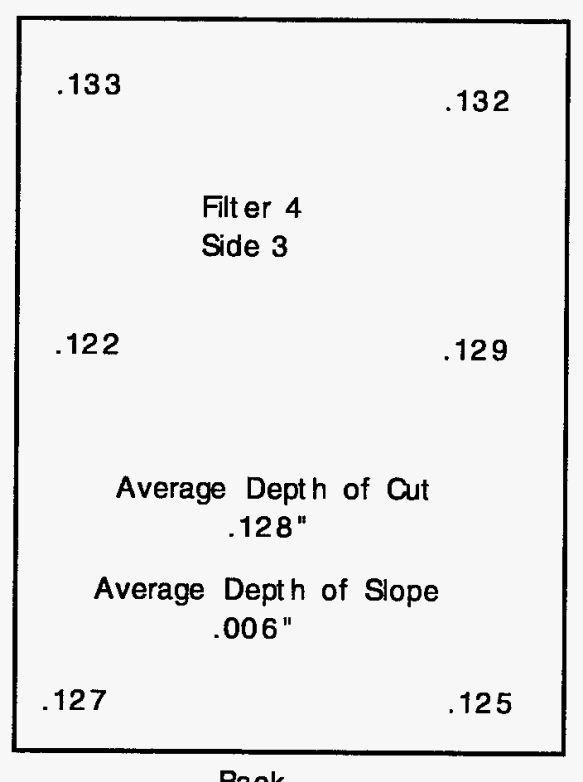

Back
Front

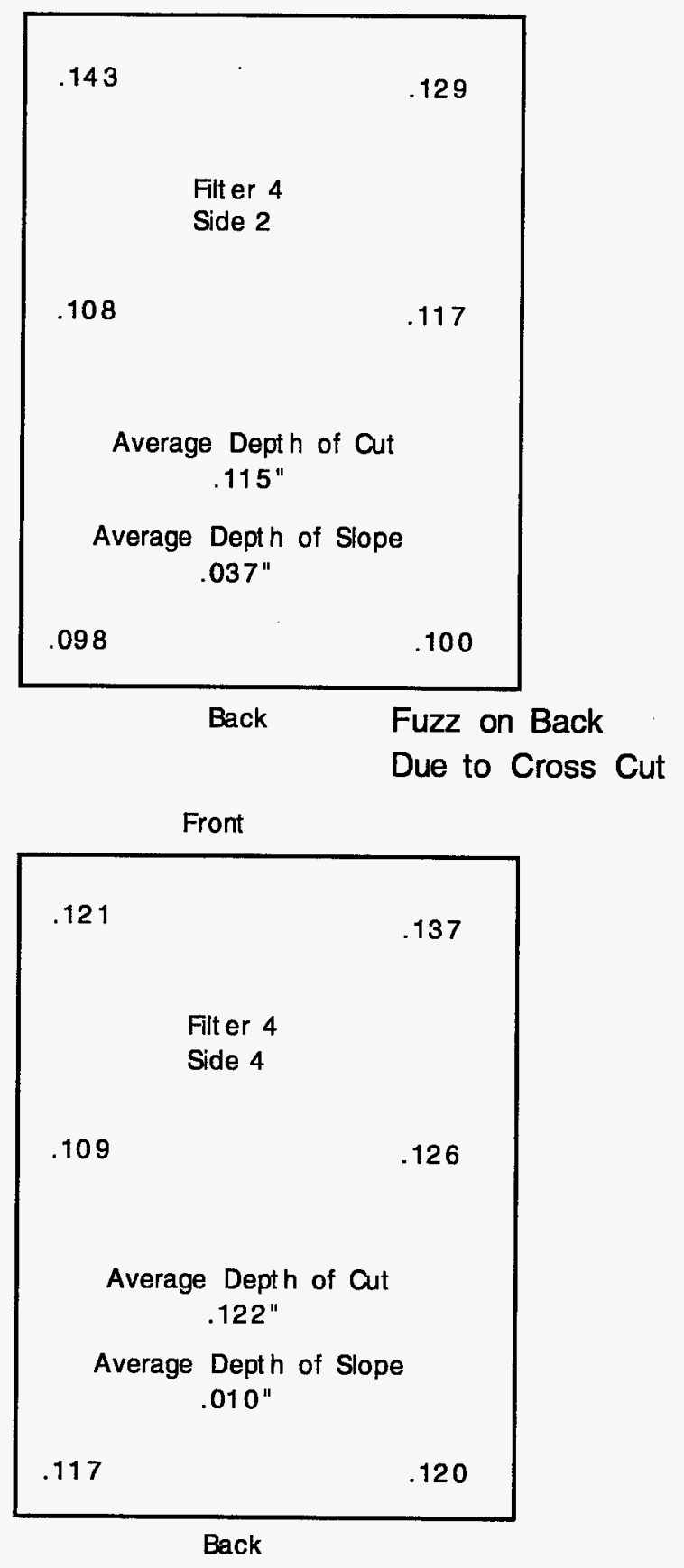


Front

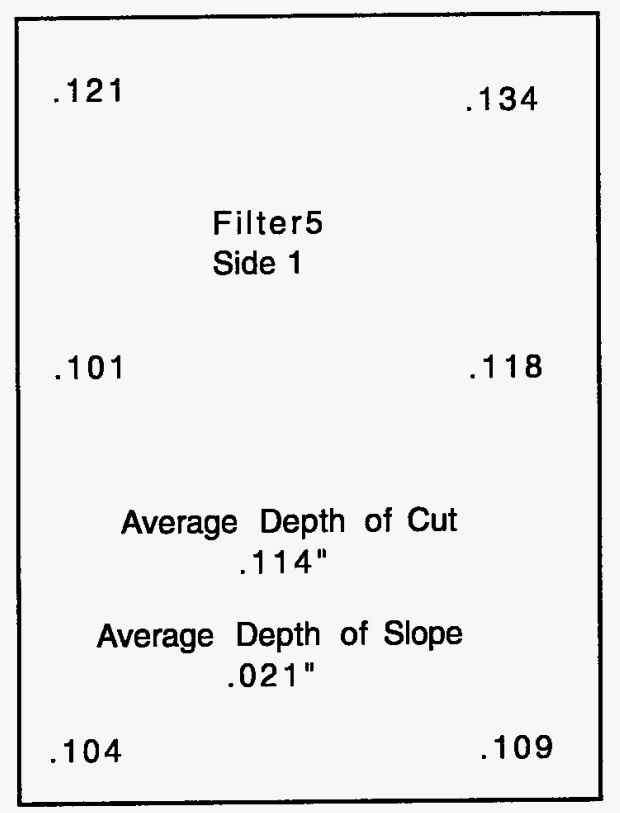

Back

Front

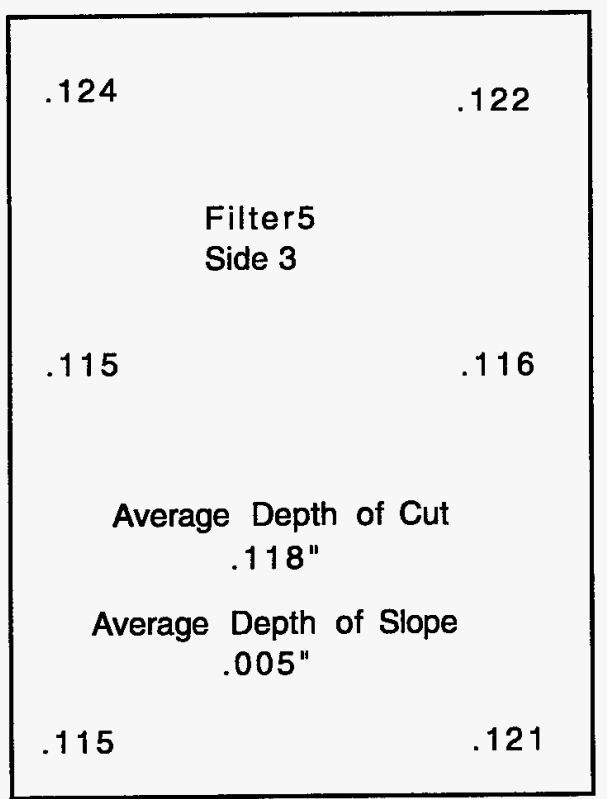

Back
Front

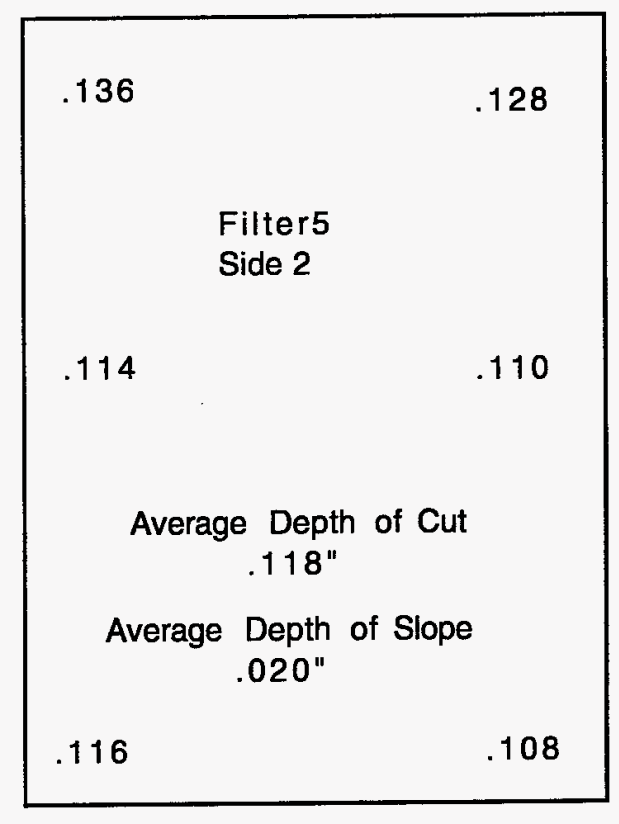

Back

Front

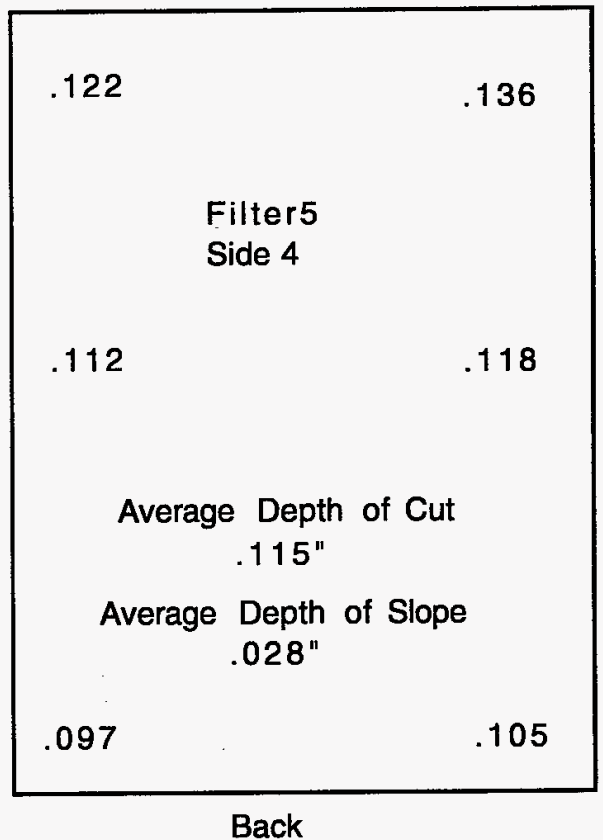

Fuzz on Back Due

to Cross Cut 
Front

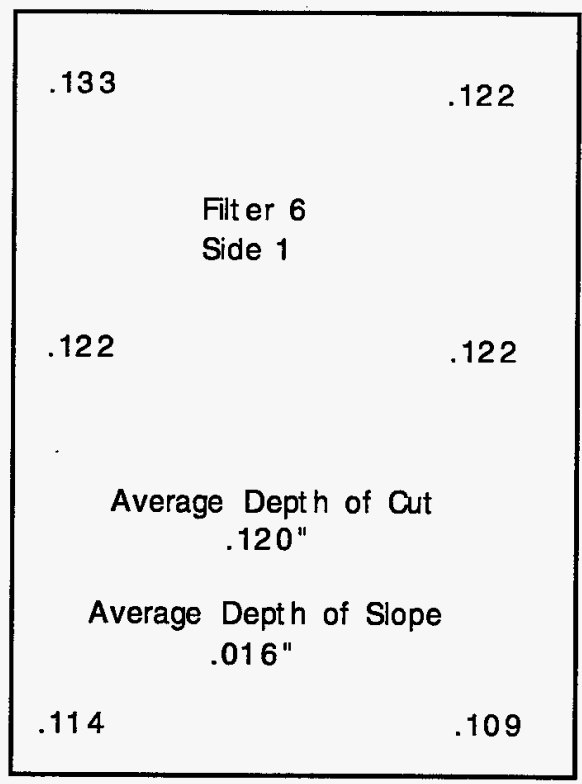

Back

Front

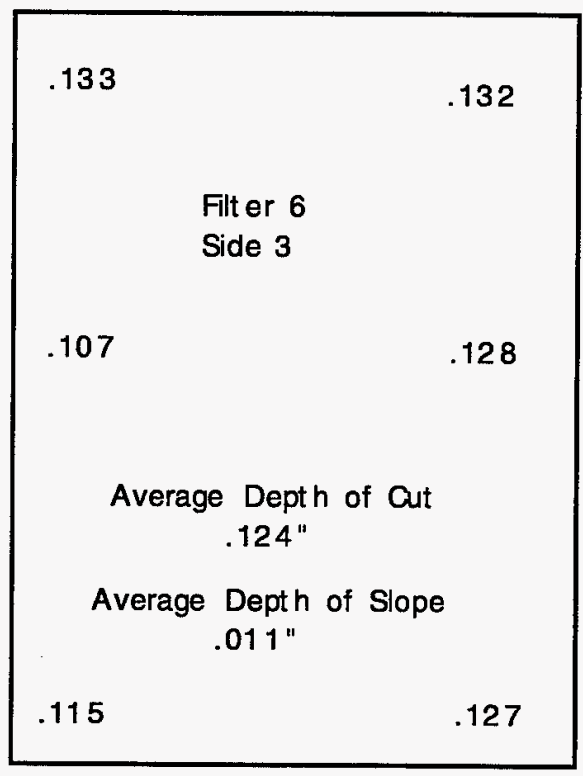

Back
Front

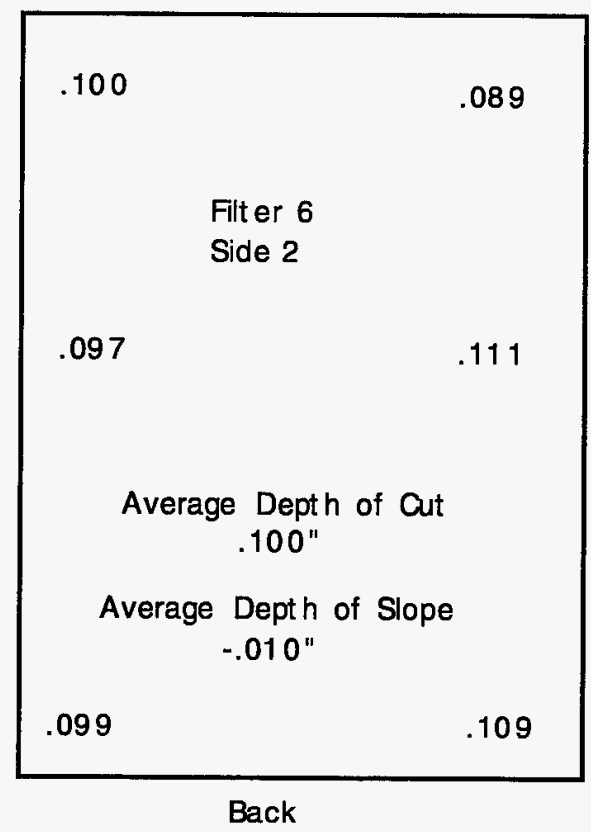

Front

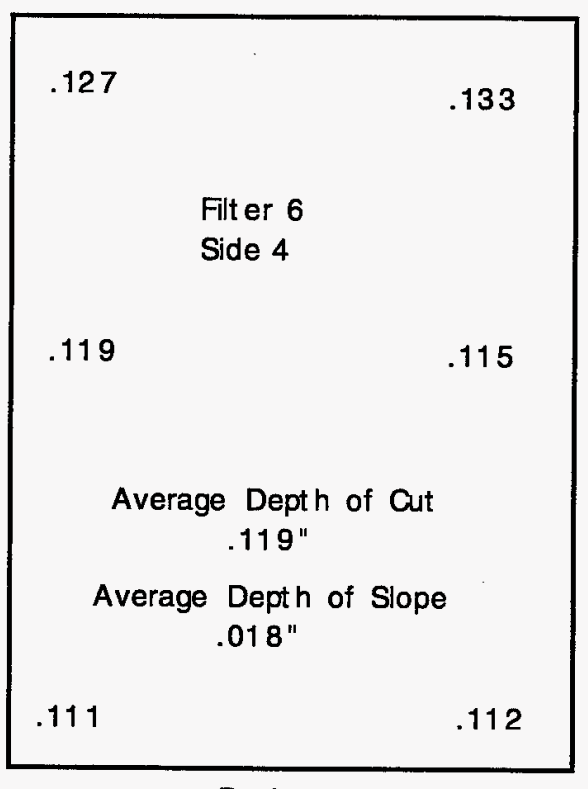

Back 
Front

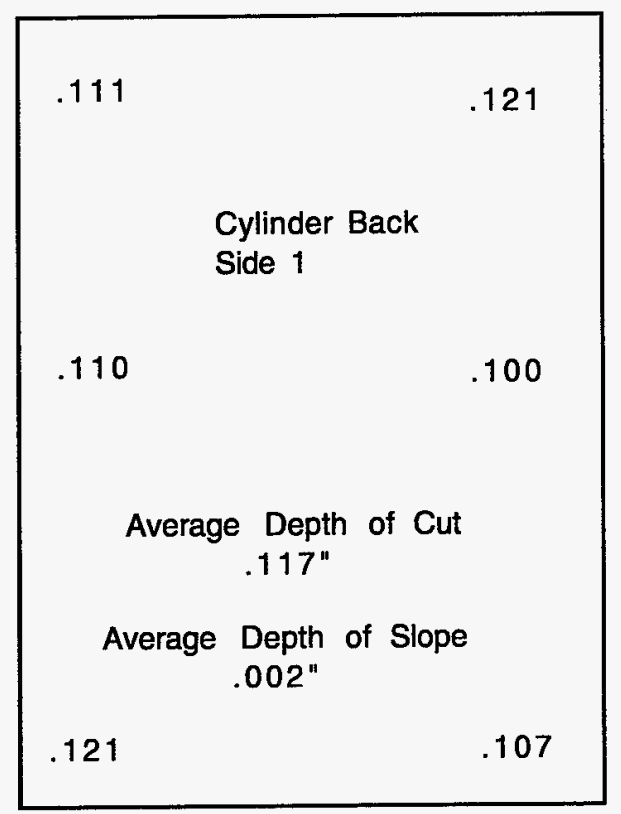

Back

Front

\begin{tabular}{|c|c|c|}
\hline \multirow[t]{2}{*}{.96} & & .102 \\
\hline & $\begin{array}{l}\text { Cylinder Back } \\
\text { Side } 3\end{array}$ & \\
\hline 106 & & .110 \\
\hline Average & $\begin{array}{l}\text { Je Depth of Cut } \\
.107^{\prime \prime}\end{array}$ & \\
\hline Average & $\begin{array}{l}\text { Depth of Slope } \\
-.017^{\prime \prime}\end{array}$ & \\
\hline .116 & & .116 \\
\hline
\end{tabular}

Back
Front

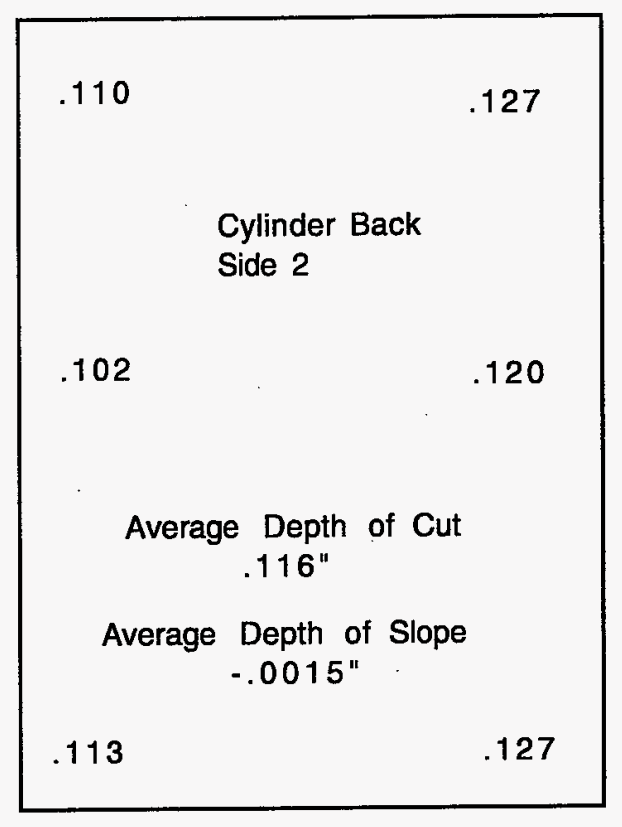

Back

Front

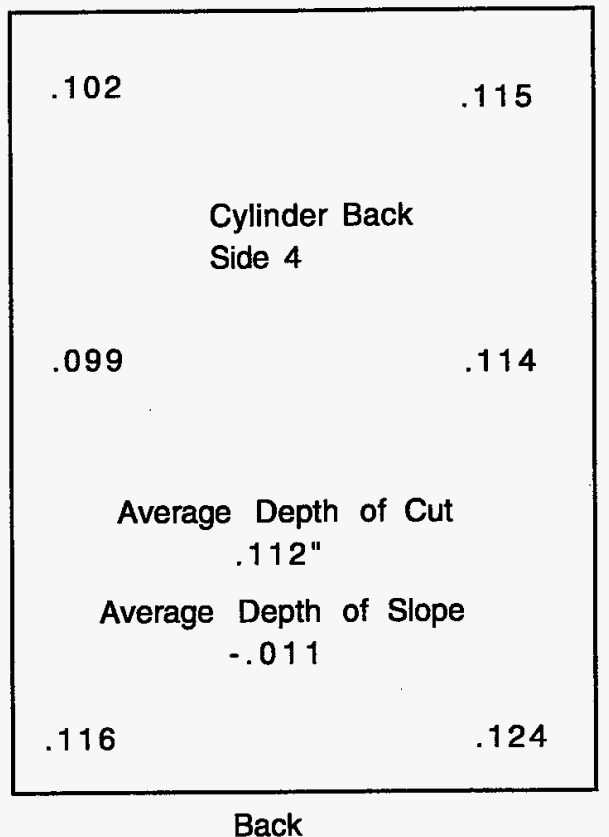

Back 
Front

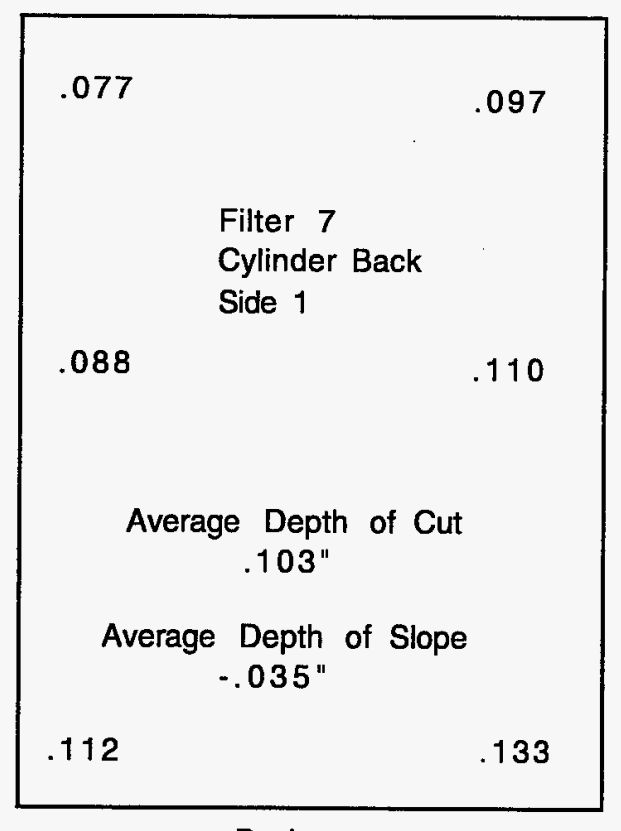

Back

Front

\begin{tabular}{|c|c|c|}
\hline \multirow[t]{2}{*}{.070} & \multirow[b]{2}{*}{$\begin{array}{l}\text { Filter } 7 \\
\text { Cylinder Back } \\
\text { Side } 3\end{array}$} & .066 \\
\hline & & \\
\hline .089 & & .090 \\
\hline Averag & $\begin{array}{l}\text { Je Depth of Cut } \\
.091^{\prime \prime}\end{array}$ & \\
\hline Average & $\begin{array}{l}\text { Depth of Slope } \\
-.052^{\prime \prime}\end{array}$ & \\
\hline 125 & & .105 \\
\hline
\end{tabular}

Back
Front

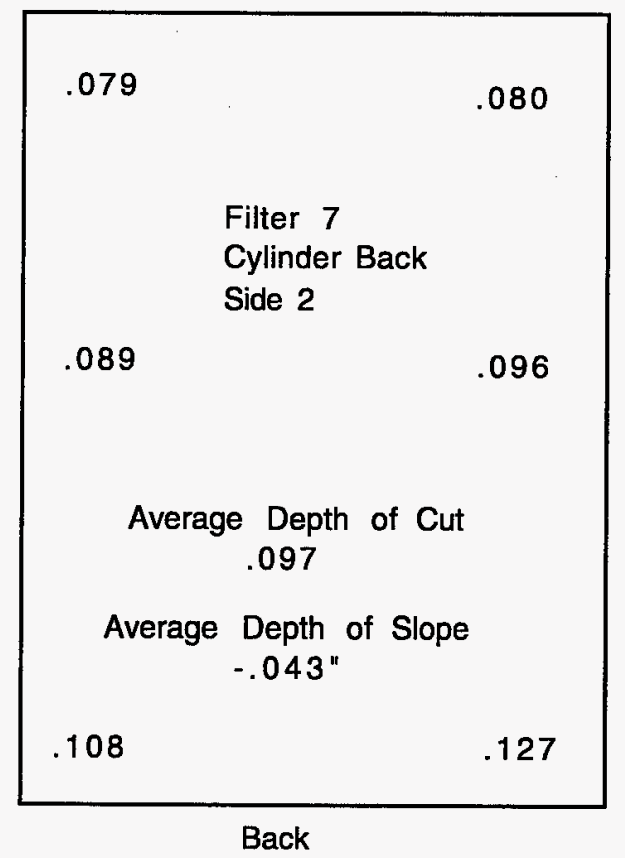

Front

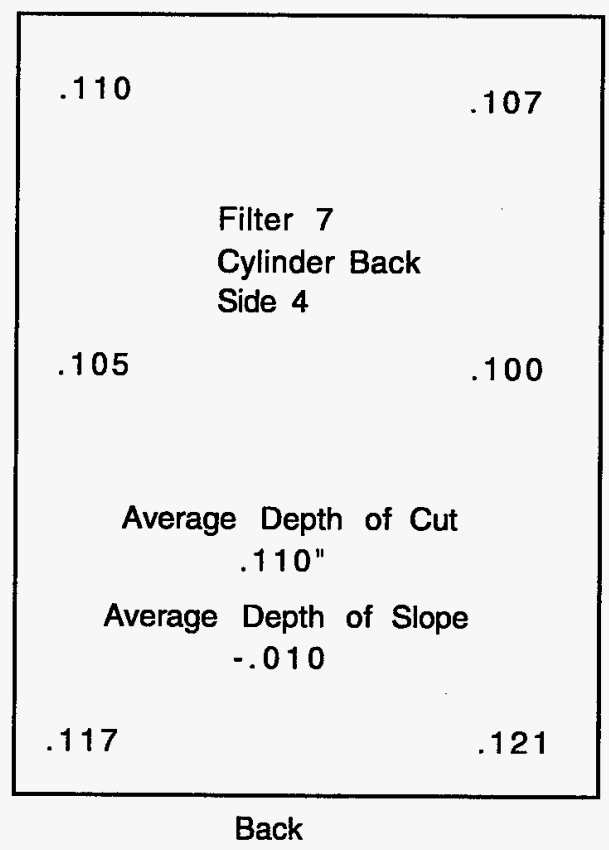


Front

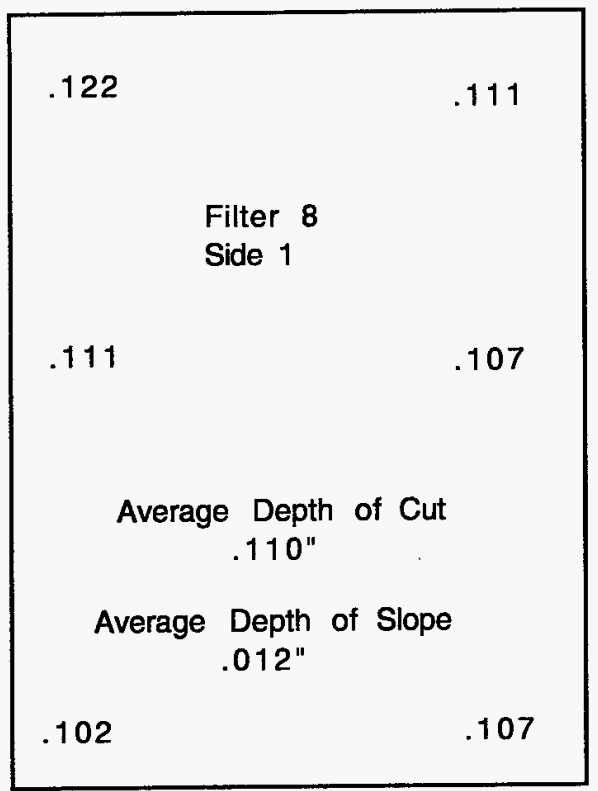

Back

Front

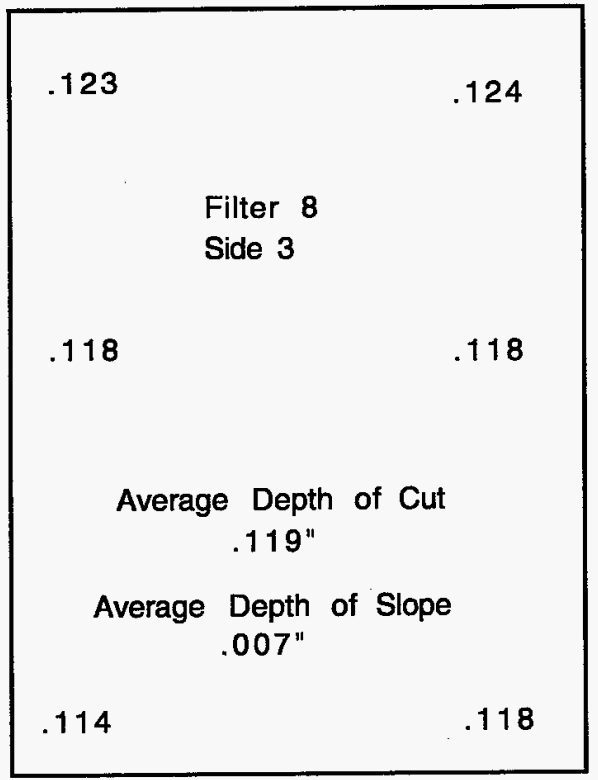

Back
Front

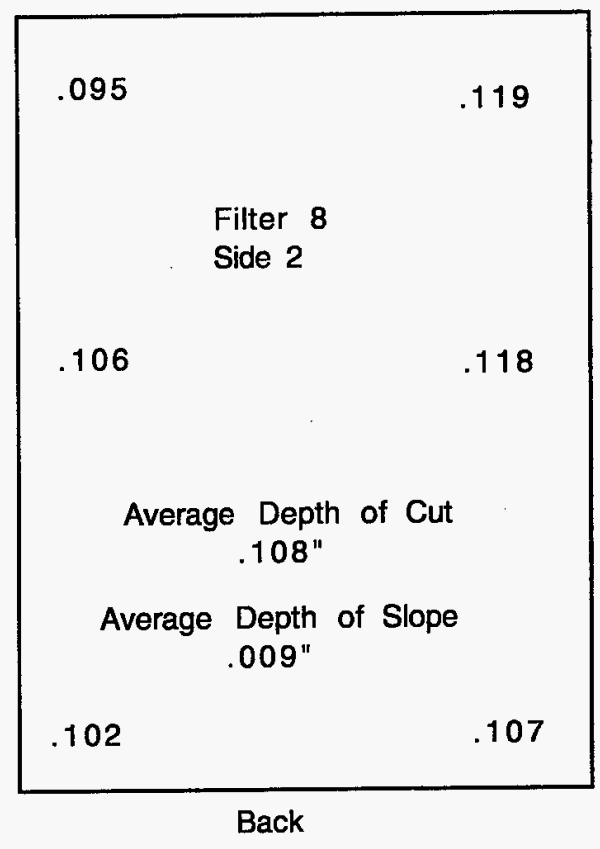

Front

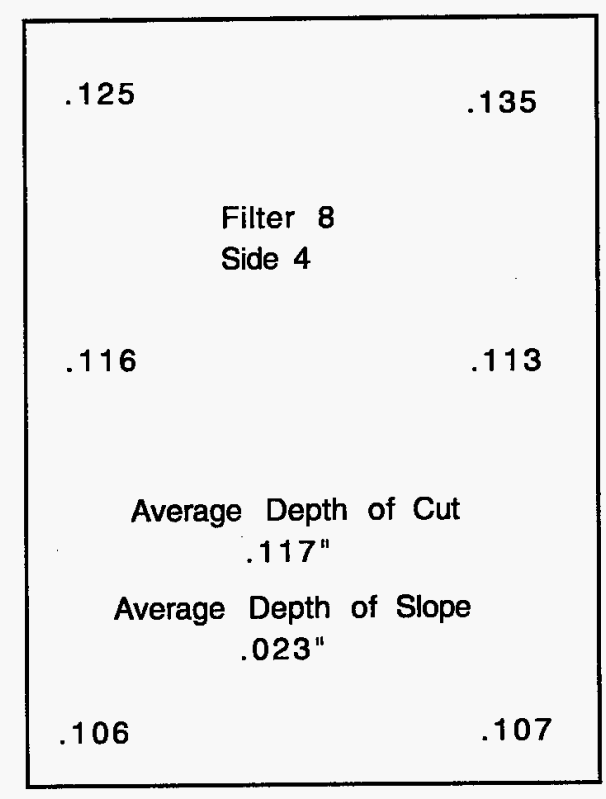

Back 
Front

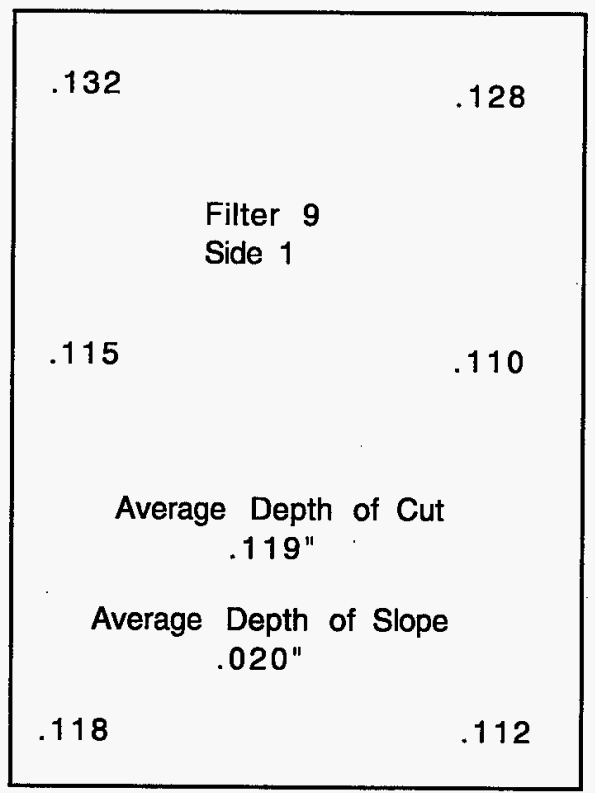

Back

Front

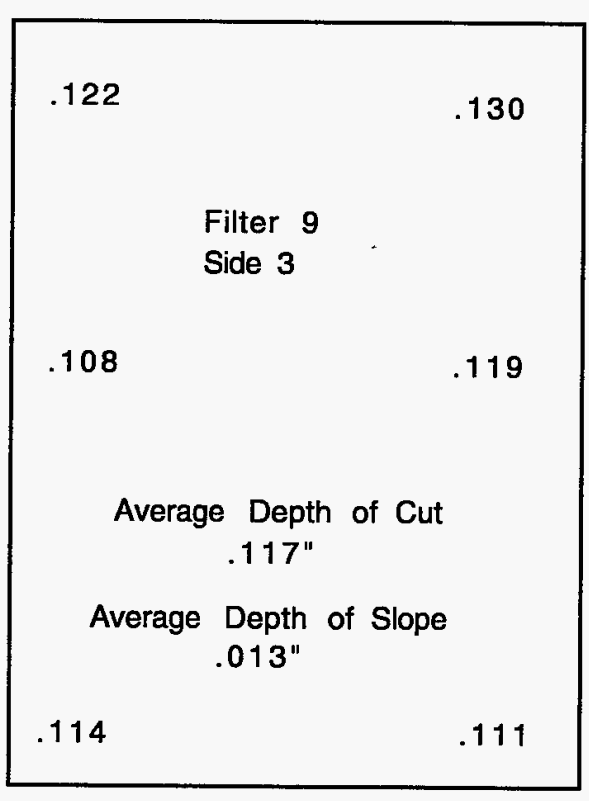

Back
Front

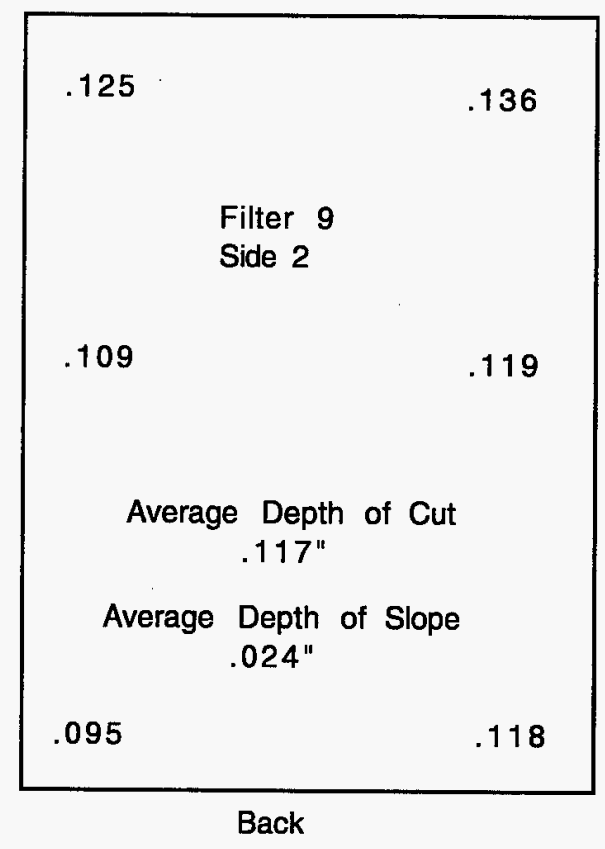

Front

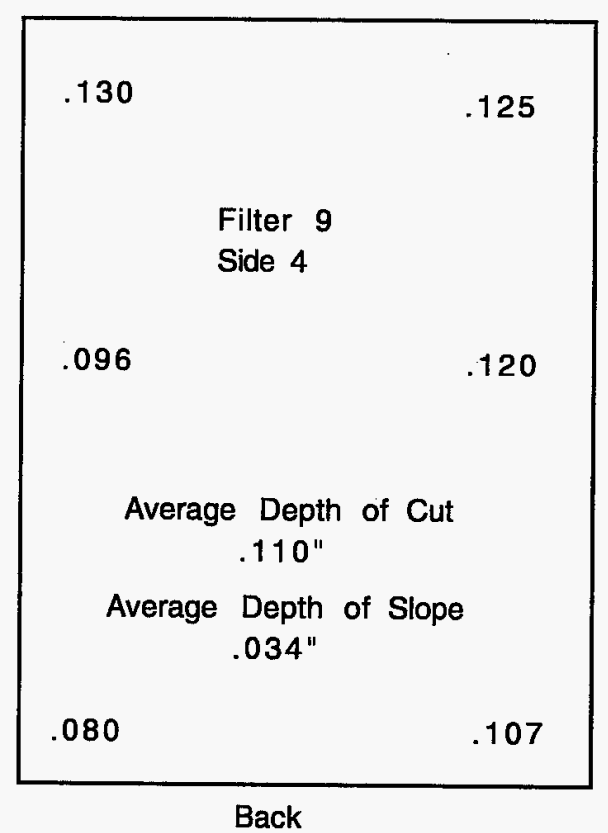




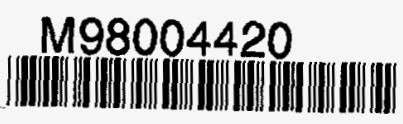

Report Number (1 LA- L $13407-M S$

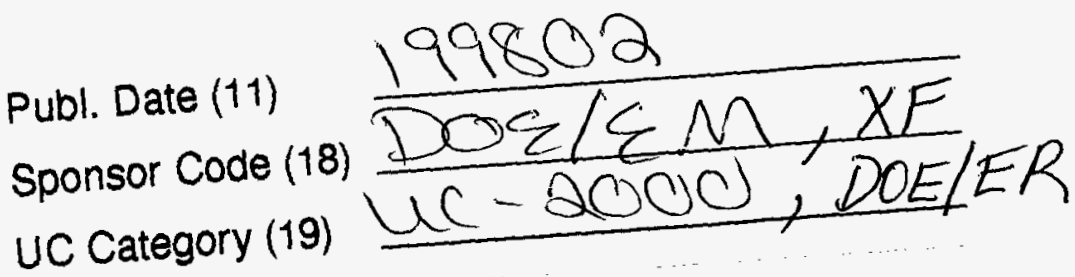


This report has been reproduced directly from the best available copy.

It is available to DOE and DOE contractors from the Office of Scientific and Technical Information, P.O. Box 62,

Oak Ridge, TN 37831.

Prices are available from (615) 576-8401.

It is available to the public from the

National Technical Information Service, US Department of Commerce, 5285 Port Royal Rd.

Springfield, VA 22616. 